\title{
Learning through clamor: the allocation and perception of study time in noise
}

Article

Accepted Version

Hanczakowski, M., Beaman, C. P. and Jones, D. M. (2018) Learning through clamor: the allocation and perception of study time in noise. Journal of Experimental Psychology: General, 147 (7). pp. 1005-1022. ISSN 1939-2222 doi: https://doi.org/10.1037/xge0000449 Available at https://centaur.reading.ac.uk/76193/

It is advisable to refer to the publisher's version if you intend to cite from the work. See Guidance on citing.

To link to this article DOI: http://dx.doi.org/10.1037/xge0000449

Publisher: American Psychological Association

All outputs in CentAUR are protected by Intellectual Property Rights law, including copyright law. Copyright and IPR is retained by the creators or other copyright holders. Terms and conditions for use of this material are defined in the End User Agreement.

\section{www.reading.ac.uk/centaur}

\section{CentAUR}

Central Archive at the University of Reading 
Reading's research outputs online 
Learning through clamor: The allocation and perception of study time in noise

\author{
Maciej Hanczakowski \\ Tenczynek, Poland \\ C. Philip Beaman
}

School of Psychology \& Clinical Language Sciences, University of Reading, UK

Dylan M. Jones

School of Psychology, Cardiff University, UK

\title{
Author Notes
}

The research reported in this article was supported by Economic and Social Research Council (UK) grant ES/L00710X/1 awarded to Dylan Jones and Philip Beaman. Parts of this research were previously presented to meetings of the Experimental Psychology Society and the Psychonomic Society.

The data for the present study can be found at https://osf.io/yrm9q/?view_only=99944e6431b3448da0762b51380ac883. 
Correspondence concerning this article should be addressed to Maciej Hanczakowski; email: maciej.hanczakowski@gmail.com.

\section{Abstract}

Memory tasks involve a degree of judgment and strategic decision-making, based upon the perceived benefits of particular learning, maintenance and recall strategies. The consequences of these metacognitive judgments for memory have been amply documented under experimental conditions that require participants to focus upon a task in the absence of distractors. Eight experiments consider the impact of less benign environmental conditions-specifically, the presence of distracting speech-upon the metacognitive aspects of memory. Distraction reliably disrupted free recall and, as indicated by Judgments of Learning, participants were aware of this effect. However, because participants did not adjust study time in compensation, the distraction effect was exaggerated relative to experimenter-imposed presentation rates. This finding appears to be the consequence of distraction-induced disruption of time perception at encoding, rather than any deliberate strategy. The results highlight the need to consider the impact of more challenging environments on metacognition generally.

Keywords: Self-regulation, Study time, Distraction, Time perception 
Learning through clamor: The allocation and perception of study time in noise

When deliberately learning materials for any upcoming test, people face two major challenges. Not only do they need to engage memory processes to encode the to-be-remembered materials, which may involve some effort, they also need to make strategic choices of how and what to learn. The most basic choice people face is about how much time to devote to the learning process. Numerous studies have considered the issue of how study time is distributed among various parts of to-be-remembered materials (see Dunlosky \& Ariel, 2011a, for a recent review). The studies conducted in this tradition involve participants performing memory tasks in laboratories, striving to learn words, pairs of words or short text passages. A ubiquitous feature of such studies is that they are conducted under well-controlled conditions, where participants are tested individually in a quiet environment aiming at minimizing the influence of all external factors that could interfere with efficient memorizing and the deployment of efficient learning strategies. Learning in real life is often more clamorous than this experimental ideal. Outside psychological laboratories, people might be obliged to learn under less optimal conditions that include the presence of noise or interruptions. For example, a survey of 140 schools in London (Shield \& Dockrell, 2004) revealed that the average ambient noise in occupied classrooms was $72 \mathrm{~dB}(\mathrm{~A})$, much higher than the average ambient noise level in unoccupied classrooms - although this itself was a surprisingly high $47 \mathrm{~dB}(\mathrm{~A})$ (predominantly from heating, external traffic noise, and "leakage" from nearby rooms and corridors). The $25 \mathrm{~dB}(\mathrm{~A})$ difference is likely to be mostly accounted for primarily by background speech and "babble". This situation is vastly different to the one usually pursued in empirical studies on self-regulated learning. The effects of noise on educational attainment are well-documented (e.g., Shield \& Dockrell, 2008) but are not limited to school-settings or school-age children. Numerous studies attest to the similarly disruptive effects on memory of distracting sound - in particular speech - amongst adults (see Banbury, Macken, Tremblay, \& Jones, 2001; Beaman, 2005, for reviews) with tests of distraction conducted in lecture theatres (Shelton, Elliott, Eaves \& Exner, 2009) and recordings taken in situ in real offices showing comparable effects to speech and other distracting stimuli constructed within 
the laboratory (e.g., Banbury \& Berry, 1998; Perham, Hodgetts \& Banbury, 2013). All these studies pose a question regarding self-regulation in non-optimal environments. The purpose of the present study is to launch a new avenue of inquiry into the effects of environmental factors, such as noise, on the strategic and metacognitive aspects of the learning process by examining study time allocation in response to auditory distraction present in the environment.

A metacognitive approach to remembering posits constant monitoring of memory processes of encoding and retrieval as a basis for decisions taken to govern the process of remembering (Nelson \& Narens, 1990). These include, for example, decisions on how much study time should be allocated to various items (Ariel, 2013; Castel, Murayama, Friedman, McGillivray, \& Link, 2013; Dunlosky \& Thiede, 1998; Metcalfe, 2002; Thiede \& Dunlosky, 1999; Soderstrom \& Bjork, 2014), which items to restudy should the opportunity arise (Ariel, Dunlosky, \& Bailey, 2009; Hanczakowski, Zawadzka, \& Cockcroft-McKay, 2014; Kornell \& Metcalfe, 2006; Metcalfe \& Finn, 2008; Nelson, Dunlosky, Graf, \& Narens, 1994; Tullis \& Benjamin, 2012), and when to terminate memory search (Brewer, Marsh, Clark-Foos, \& Meeks, 2010; Hanczakowski, Zawadzka, Collie, \& Macken, 2017; Hussey, Dougherty, Harbison, \& Davelaar, 2013). The prime reason for investigating metacognitive monitoring and control is that effective metacognitive control, when informed by accurate monitoring, has the potential to improve memory performance. Although inefficient metacognitive control has also been reported, particularly when the goal is one of long-term retention (e.g., Benjamin \& Bird, 2006; Karpicke, 2009), research focused on immediate tests indicates that, by and large, giving people more control and more opportunity to take their own decisions in a memory task results in superior performance.For example, Tullis and Benjamin (2011) found that participants given control over the time spent studying memoranda remembered more than participants who were precluded from exerting such control (see also de Jonge, Tabbers, Pecher, Jang, \& Zeelenberg, 2015; Mazzoni \& Cornoldi, 1993). Similarly, investigations that looked at decisions about which items to restudy by either honoring or changing their re-study choices found that participants who exert control over their restudy decisions perform better than participants who do not exert such control 
(Kornell \& Metcalfe, 2006; Tullis \& Benjamin, 2012). Metacognitive control has also been shown to allow for compensating for increased difficulty of learning under divided attention, when people were able to focus on the most important information despite increased overall difficulty posed by the learning environment (Middlebrooks, Kerr, \& Castel, 2017).

Two preconditions are required for successful self-regulation of remembering. Firstly, people need to accurately monitor their own basic memory processes. In their study, Tullis and Benjamin (2011) showed that exerting control over study times yields benefits to memory performance only when participants devote more study time to items that are most difficult to learn. This means that, in order to deploy effective study-time allocation strategies, the difficulty of learning the various items must be apparent. Secondly, accurate metacognitive monitoring must appropriately inform metacognitive control:. Judgments-of-learning (JOLs), tapping people's appraisal of the effectiveness of the learning process, inform decisions about when to terminate study (e.g., Son \& Metcalfe, 2000; Thiede \& Dunlosky, 1998), which item(s) to restudy (e.g., Kornell \& Metcalfe, 2006), and how to schedule restudy sessions (e.g., Benjamin \& Bird, 2006). These examples demonstrate the necessary link between monitoring and the decisions made in a memory task to allow for effective selfregulation of remembering.

Enhanced performance when individuals control their own study times represents a particular instance of appropriate metacognitive control grounded in accurate monitoring, because more study time is devoted to items which are accurately appraised as being more difficult to learn (Tullis \& Benjamin, 2011, see also Dunlosky \& Thiede, 1999; Son \& Metcalfe, 2000). However, the demands posed by the environment - for example in the form of background speech or other noise - are known to affect the effectiveness of learning (see Banbury et al., 2001; Beaman, 2005; Hughes \& Jones, 2003; Jones, Hughes \& Macken, 2010). The present study thus assesses whether the same metacognitive dynamics - accurate monitoring leading to appropriate control yielding performance 
benefits - occur when difficulty of learning is increased by environmental conditions of noise, rather than difficulty of to-be-learned materials.

Three aspects of strategic learning under auditory distraction are addressed: monitoring, control and the effects of self-regulation. The main question of monitoring concerns whether people are aware of the negative influence of noise on the efficacy of the learning process. In a recent study (Hanczakowski, Beaman, \& Jones, 2017), we found that people expect poorer memory when learning is accompanied by irrelevant auditory distraction, as reflected by lower JOLs, suggesting an accurate reflection of the environmental challenges for learning. However, these results must be viewed as preliminary because item JOLs - judgments provided after each study item - were used. Item JOLs are often assumed to reflect the fluency of processing (e.g., Rhodes \& Castel, 2008; Undorf \& Erdfelder, 2015), but less fluent processing may not, by itself, be sufficient to alert people to the fact that learning has become more difficult. In other words, lower item JOLs may not reflect the insight required to modify learning strategies (see Koriat, Ma'ayan, \& Nussinson, 2006, for a discussion of how differences in item JOLs may be a result, rather than a cause, of changes in learning strategies). What may be necessary for effective control is a belief that noise impedes learning. Beliefs can be assessed with aggregate JOLs which are often sensitive to factors different from those which influence item JOLs (e.g., Frank \& Kuhlmann, 2017). Thus, in the present study we investigate the effect of auditory distraction on the metacognitive monitoring of learning by examining how noise impacts on aggregate rather than item JOLs.

The second issue examined here is how noise affects study time allocation. If global assessments of learning (in the form of aggregate JOLs) indicate a belief that auditory distraction impedes learning, then the next step in investigating strategic learning in noisy environments is to assess whether accurate metacognitive monitoring shapes metacognitive control. Previous research on study time allocation shows that people devote more study time when they expect learning to be impeded (e.g., Dunlosky \& Thiede, 1998; Thiede \& Dunlosky, 1999; Tullis \& Benajmin, 2011). These 
previous studies looked at the manipulation of item difficulty but one can derive a parallel prediction for the manipulation of environmental demands, in which participants would be expected to devote more study time when learning is impeded by auditory distraction.

The final issue concerns the performance effect of changes in study time allocation. Under favorable conditions, greater control over memory processes confers benefits for memory performance (e.g., Kornell \& Metcalfe, 2006; Tullis \& Benjamin, 2011). One question here is whether participants still benefit from the option to control their study under auditory distraction. Thus, we address the impact of environmental effects on the potential benefits of self-regulation. A second question is concerned with the impact of self-regulation on environmental effects: that is, whether self-regulation modulates the effect distraction exerts on memory performance. For example, people who engage in self-regulated study may recruit compensatory strategies - such as extended study - to reduce harmful consequences of changes in environment (see Middlebrooks et al., 2017, for a related discussion).

To summarize, in the present study we examined metacognitive monitoring, metacognitive control over study times, and memory performance in a memory task, all performed under varying environmental demands. In six experiments, we visually presented participants with lists of single words for study and subsequent recall. Some lists were accompanied by auditory distractors and some presented in silence. We used this set-up to investigate whether participants correctly predict reduced performance under auditory distraction, extend study times in order to compensate for the effect of distraction and thus not only show improved performance in the self-regulated condition but also reduce the negative impact of auditory distraction while engaging in self-regulated studyln the seventh experiment, for comparison, we assessed the impact of auditory distraction on control over presentation times in a non-memory task. . In the eighth experiment, we changed materials to pairs of words in order to assess one of the hypotheses regarding the impact of auditory distraction on study times. 


\section{Experiment 1}

This experiment investigated metacognitive monitoring in the form of aggregate JOLs and metacognitive control in the form of study-time allocation. The environmental conditions were changed by varying the presence of auditory distraction during learning. Two research issues were investigated. The first concerned the accuracy of metacognitive monitoring. If metacognitive monitoring is to be accurate, it needs to apprehend a change in the effectiveness of the learning process brought about by changes in environmental conditions. Thus, accurate monitoring, would be revealed in lower aggregate JOLs provided after lists accompanied by auditory distraction, a manipulation known to impede the process of learning (e.g., Miles, Jones \& Madden, 1991).

The second issue addressed in Experiment 1 concerned metacognitive control exerted over study times. If participants are capable of accurate monitoring in the presence of auditory distraction, interest naturally centers on whether monitoring informs study time allocation. The usual observation from studies of self-regulated study is that people devote more study time to materials they deem more difficult to learn (cf. Son \& Metcalfe, 2000). If the manipulation of environmental conditions has a parallel effect to the manipulation of difficulty of materials, we could expect longer study times in the presence of auditory distraction that might counter the effect of distraction itself.

The present experiment also manipulated the semantic relationship between auditory distractors and the to-be-remembered information. Previous research suggests that demands posed by auditory distraction are particularly high when distraction is semantically related to to-beremembered information (e.g., Beaman, 2004; Beaman, Hanczakowski, Hodgetts, Marsh, \& Jones, 2013; Hanczakowski, Beaman, \& Jones, 2016; Marsh, Hughes, \& Jones, 2008; 2009; Neely \& LeCompte, 1999; but see Hanczakowski et al., 2017, for contrasting results). For example, Marsh et al. (2008) demonstrated that recall of lists of categorized words is depressed more when auditory distractors consist of spoken words from the same category than when they consist of spoken words 
from a different category. Thus, the manipulation of semantic relationship was introduced here to further adjust the demands posed by environmental conditions for the learning process.

\section{Method}

Participants. Thirty undergraduates from Cardiff University participated in the experiment for course credit or small monetary compensation. The sample size was chosen to be comparable in power to the study by Hanczakowski et al. (2017, Experiment 1), where 23 participants were sufficient to detect the effects of auditory distraction on both recall and item JOLs. The study was approved by the ethics committee at Cardiff University.

Materials and design. Thirty categories from the category norms by Yoon et al. (2004) were chosen. Each category served as a source of randomly chosen 15 study words and 15 words used as auditory distracters. Thirty categories were first divided into two sets of 15 categories. Only one set of 15 categories was used as a source of study words for any given participant and this assignment of sets was counterbalanced across participants. Both sets of 15 categories were further divided into three subsets of five categories each. These subsets were assigned to three different experimental conditions and this assignment was also counterbalanced across participants. The three experimental conditions were: 1) the quiet condition, in which study lists were presented in silence, 2) semantically related auditory distraction, in which study lists were accompanied by auditory presentation of words from the same semantic category as to-be-remembered words in a given list, 3) semantically unrelated auditory distraction, in which study lists were accompanied by auditory presentation of words from a different semantic category. In the lists assigned to the related distraction condition, words from the same category served as both study words and auditory distraction. In the lists assigned to the unrelated distraction condition, auditory distracters were taken from a yoked category from the set of 15 categories that was not used as a source of study items for a given participant. The presentation of the lists was blocked so that there were five blocks 
of three different lists, one from each of the three experimental conditions. The order of the blocks and lists within blocks was randomized anew for each participant.

Words from each of the 30 categories used were recorded individually in a female voice and used as auditory distraction. The individual words were then edited to create a continuous stream of 15 words spoken at a rate of one word every $750 \mathrm{~ms}$. This sequence was played as a loop during study in conditions of distraction.

Procedure. Participants were tested individually or in small groups of up to three participants at the same time. During the entire procedure they wore noise-cancelling headphones. The procedure consisted of a study, judgment, and recall phases for 15 lists of categorized words. For each study list, 15 study words were individually presented in the middle of a computer screen. Participants were instructed to study the words for as long as they deemed necessary and then move to the next word by pressing the spacebar. Immediately after the termination of the last of the study words, participants were asked how many out of the preceding list of 15 words they expected to freely recall. Participants were given as much time as they required to provide this aggregate JOL. Immediately after typing-in the judgment, participants were administered a free recall test in which they were asked to type in all the words they could remember from the preceding study list. They were given 60 seconds to complete the free recall task before the presentation of the next list.

\section{Results and discussion}

Correct recall and aggregate JOLs averaged across lists are presented in Figure 1. Mean study times are presented in Figure 2. Correct recall was examined using a one-way Analysis of Variance (ANOVA) with three levels: quiet condition, related distraction, unrelated distraction. This yielded a significant effect, $F(2,58)=27.58, M S E=.004, p<.001, \eta_{p}^{2}=.487$. Planned comparisons revealed that performance suffered in the unrelated distraction condition as compared to the quiet condition, $t(29)=4.66, S E=.02, p<.001, d=0.86$. Performance seemed to be further depressed in the related distraction compared to the unrelated distraction condition, although this effect was not 
significant, $t(29)=2.00, S E=.01, p=.055, d=0.28$. These results show the usual pattern of impairment caused by auditory distraction and, importantly, this standard pattern emerged under conditions in which participants were given control over their own study times. This suggests that exerting metacognitive control over study does not eliminate the distraction effects.

\section{FIGURES ONE AND TWO ABOUT HERE}

In the present study, we did not impose any delay between study and recall which were separated only by a JOL prompt. In this set-up, it is possible that distraction only affects a portion of the list (primacy or recncy). To assess this, the serial position curves are presented in Figure 3. These curves show a recency effect in the quiet condition but they also show a prominent primacy effect. Both recency and primacy are clearly reduced in the distraction conditions for which serial position curves are largely flat, indicating that recall was not dominated by only few words from the end of each list and thus demonstrating that the effects are not limited to any putative short-term buffer. Note that the interpretation of serial position curves for free recall - and in particular where, if anywhere, a specialist short-term memory buffer might contribute - is disputed (e.g., Brown, Neath \& Chater, 2007; Davelaar, Goshen-Gottstein, Ashkenazi, Haarmann \& Usher, 2005; Tan \& Ward, 2000). Serial position was not included in the formal analysis for these reasons and because any interaction with auditory distraction can easily occur simply because of scalar effects across a serial position curve (Jones \& Macken, 1995) rendering such an analysis uninformative. 
The aggregate JOLs reflect participants' monitoring of the encoding process. Given that recall was clearly lower in the presence of auditory distraction, accurate monitoring should be reflected in lowered JOLs for the distraction conditions. To examine this issue, we analyzed the mean of JOLs with a one-way ANOVA, which yielded a significant effect of the experimental condition, $F(2,58)=24.43, M S E=.004, p<.001, \eta_{p}{ }^{2}=.457$. Planned comparisons revealed that participants anticipated recalling fewer words from the lists accompanied by unrelated auditory distraction than from lists studied in the quiet condition, $t(29)=4.96, S E=.02, p<.001, d=0.98$. Predictions were also numerically lower for lists studied in the related distraction compared to the unrelated distraction condition, although this effect was not significant, $t(29)=1.72, S E=.01, p=$ $.097, d=0.30$. These results indicate that participants' metacognitive monitoring was largely accurate in that it correctly factored in the reduction in recall caused by auditory distraction.

Given that participants correctly monitor the impairment caused by auditory distraction, the final issue is whether this monitoring translates into changes in metacognitive control over study times. To examine the issue, we analyzed the mean study times per word with a one-way ANOVA. We performed this analysis both for overall study times and study times with the exclusion of the first words in each of the study list, in order to remove a potential effect of delayed study initiation in the distraction conditions. The results of both analyses were identical so we report only data for the overall analysis of study times. The ANOVA yielded a significant effect of experimental condition, $F(2,58)=10.98, M S E=0.24, p<.001, \eta_{p}^{2}=.275$. Planned comparisons revealed that participants spent more time per study word in quiet compared to the unrelated distraction condition, $t(29)=$ 3.92, $S E=0.13, p<.001, d=0.71$ (see Figure 2), but there was no difference between the two distraction conditions, $t<1$. Thus, participants did not compensate for an increase in environmental demands caused by the auditory distraction. Instead, they spent significantly less time studying the words when distraction was present. 
All experiments in the present study used a multiple-list paradigm in which several lists served in each of the experimental conditions and indices of monitoring, control, and performance were averaged across lists. Since repeated cycles of learning and retrieval could affect the way metacognitive processes are deployed we reanalyzed recall, aggregate JOLs and study times with the overall ANOVAs including, beside the distraction condition factor, the factor of list $(1,2,3,4$, or 5$)$. For recall data, neither the main effect of list, $F(4,116)=1.45, p=.22$, nor the interaction of list and distraction condition, $F(8,232)=1.64, p=.11$, were significant, indicating that recall performance remained essentially unchanged throughout the task. For the study times data, the main effect of list was significant, $F(4,116)=3.50, p=.01$, which arose because participants systematically devoted less study time to words from consecutive study lists (List 1: 2926 ms, List 2: 2728 ms, List 3: 2543 ms, List 4: 2423 ms, List 5: 2395 ms). This speeding-up across lists may reflect either a practice effect or overall fatigue but, importantly, it did not interact with the distraction condition, $F(8,232)=1.64$, $p=.11$. Finally, for the JOL data, the overall ANOVA yielded no main effect of list, $F<1$, but a significant interaction with the distraction condition, $F(8,232)=3.05, p=.003$. Aggregate JOLs as a function of the distraction condition and list are given in Figure 4. This plot reveals subtle differences across distraction conditions, most notably a fall in performance predictions for the quiet condition after the first list, but it also shows that predictions for the quiet conditions were clearly higher than predictions for both distraction conditions, substantiating our claim that participants accurately predicted negative effects of noise on performance across the whole learning task. Given that the by-list analysis for the present experiment did not reveal any effects crucial for our theorizing, the same analyses for the remaining experiments are presented in supplementary materials. 
The results of Experiment 1 demonstrate that auditory distraction reliably impairs memory performance, replicating previous studies (e.g., Beaman, 2004; Macken, Mosdell, \& Jones, 1999; Marsh et al., 2008). In the present study, the overall effect of distraction was much stronger than the effect of semantic relationship between the contents of distraction and the study lists. We manipulated this semantic relationship in the hope of posing additional demands for the learning process. Since the effect of semantic relationship was small - a two percentage-point difference between related and unrelated conditions - and not the main interest for the assessed hypotheses, subsequent experiments focus exclusively on a situation in which auditory distraction is unrelated to study materials.

These results also indicate that participants' metacognitive monitoring, as tapped by aggregate JOLs, was generally sensitive to changes in environmental demands of the memory task. Participants gave lower predictions of subsequent recall performance when distraction was present. This pattern extends previous results indicating that item JOLs correctly reflect increased difficulty of learning accompanied by unrelated distraction (Hanczakowski et al., 2017). However, these results are still tentative because they were obtained in the procedure in which participants had full control over study times and thus monitoring may reflect, to some extent, the effect of curtailing study under distraction. Experiments 2-4 provide a stronger test for the accurate monitoring hypotheses, examining aggregate JOLs also in conditions in which metacognitive control over study times was precluded.

The present results show also that compensatory strategies were not deployed. Far from extending study in line with an increase in environmental demands, auditory distraction actually led to curtailled study. Thus, more challenging encoding conditions were met with a study time allocation strategy that was apparently decoupled from the accurate monitoring reflected in aggregate JOLs. This contrasts with the results of studies that looked at manipulations of internal demands posed by changes in the difficulty of the study materials. In experiments looking at how 
study time is allocated to items differing in difficulty the usual finding is that participants devote more study time to more difficult items. In a survey by Son and Metcalfe (2000), this pattern was observed in 35 out of 46 experimental conditions. In contrast to this common negative JOL-study time association for items, our results reveal a positive association, by which lists given lower JOLs are also characterized by shorter average study times. This unexpected finding is investigated further in subsequent experiments.

\section{Experiments 2-4}

Experiment 1 did not address the consequences of engaging in self-regulated study under varied environmental conditions, which requires a manipulation of allowed versus precluded metacognitive control. In our study, participants were given full opportunity to engage in metacognitive control in all conditions so although the metacognitive control strategies were not as expected, the experiment did not directly compare control and no-control conditions. As described earlier, giving control over study could enhance performance under more challenging environmental conditions, just as it apparently does when learning takes place in the quiet environment (de Jonge et al., 2015; Tullis \& Benjamin, 2011). It could also limit the harmful effect distraction has on performance, even though this effect seems unlikely given the absence of compensatory strategies in study-time allocation revealed in Experiment 1. Experiments 2-4 were conducted to assess how recall performance is shaped by engagement in self-regulated study. Also, including a condition in which study times were imposed by the experimenter, allows for assessing monitoring accuracy when control is precluded.

Experiments 2-4 differed only in materials presented for study and thus they are described jointly here. Experiment 2 used the categorized lists employed in Experiment 1, Experiment 3 used categorized lists composed of items taken from three different categories, whereas Experiment 4 used uncategorized words as study materials. Three versions of the same design were used because 
Experiment 2 produced an unexpected pattern of results, as described next. Variants of this experiment were then conducted to assess the generalizability of these findings.

\section{Method}

Participants. Eighty-nine participants were recruited. Thirty participants completed Experiment 2, twenty-nine participants completed Experiment 3, and thirty participants completed Experiment 4. Participants were undergraduates from Cardiff University who participated in the experiments for course credit or small monetary compensation.

Materials and design. Participants studied 20 lists consisting of 15 words each. For Experiments 2 and 3, twenty of the thirty categories used in Experiment 1 were included as the source of study words. The remaining ten categories were used as a source of auditory distracters. The experiments differed in terms of list composition, with Experiment 2 using one-category lists that were used previously in Experiment 1, whereas for Experiment 3, categories were divided into three sets of five words and these five-word blocks were randomly shuffled so as to create 20 lists composed of words from three different categories each. For Experiment 4, 300 words were chosen from the MRC linguistic database and these were used to create 20 lists of uncategorized words. The same auditory distraction was used in all experiments.

The design of all experiments was 2 (distraction: present vs. absent) $\times 2$ (control over study times: participant vs. experimenter), with both factors manipulated within participants. Five lists were included for each condition, and the assignment of lists to the conditions was counterbalanced across participants. The factor of control over study times was manipulated between experimental blocks so that participants completed 10 lists controlling study times and 10 lists with study times set by the experimenter in two blocks. The order of the blocks was counterbalanced across participants. The distraction factor was manipulated between lists but within blocks. 
Procedure. The procedure for conditions in which participants controlled their study times closely followed the procedure of Experiment 1. In the condition in which participants' control over study times was precluded, study times were set to 3 seconds for all words. This value corresponds closely to the value of 2.94 seconds, which was the mean of study times in the control condition of Experiment 1.

\section{Results and discussion}

The descriptive statistics for Experiments 2-4 can be found in Table 1 (recall and JOL data) and Table 2 (study time data).

\section{Experiment 2}

We first assessed whether the effects observed in Experiment 1 for the measures of metacognitive monitoring and control were replicated. A 2 (distraction: present vs. absent) $\times 2$ (control over study times: participant vs. experimenter) within-participants ANOVA on the mean of aggregate JOLs yielded a significant main effect of distraction, $F(1,29)=31.51, M S E=.002, p<.001$, $\eta_{p}^{2}=.521$, but no effect of control and no interaction, $F s<1$. Thus, similarly to Experiment 1 , participants expected to recall fewer items when distraction was present at study and, importantly, this effect emerged also when metacognitive control over study times was precluded. A planned comparison of mean study times in the condition of participants' control over study times yielded a significant effect, $t(29)=2.32, S E=.10, p=.028, d=0.42$, thus replicating the effect of curtailed study under distraction.

A further set of analyses concerns recall performance. A 2 (distraction) $\times 2$ (control) withinparticipants ANOVA on correct recall yielded a significant main effect of distraction, $F(1,29)=13.96$, $M S E=.004, p=.001, \eta_{p}^{2}=.325$, demonstrating that distraction impaired memory performance. The main effect of control however was not significant and neither was the interaction, $F s<1$. These results are surprising inasmuch as they fail to show the benefits to memory performance of self- 
regulation even under favorable conditions of no distraction. Given the lack of this basic effect, it is perhaps unsurprising that under conditions of more environmental demands imposed by auditory distraction any benefits of exerting metacognitive control also failed to emerge. It is worth noting, however, that for the present experiment study times in the quiet condition when controlled by participants were notably shorter (2.44 s) than study times observed in the comparable condition of Experiment $1(2.94 \mathrm{~s})$, which also served as the source of the 3 second presentation time used in the comparison condition of experimenter-controlled study in the present experiment. Effectively, participants had less time overall when they controlled study than when they were denied such control, which could contribute to the failure to benefit from self-regulation in the quiet condition.

\section{Experiment 3}

The analysis of the mean aggregate JOLs with a 2 (distraction: present vs. absent) $\times 2$ (control over study times: participant vs. experimenter) within-participants ANOVA ${ }^{1}$ yielded a significant main effect of distraction, $F(1,27)=41.67, M S E=.003, p<.001, \eta_{p}{ }^{2}=.607$. Thus, similarly to both Experiments 1 and 2, participants expected to recall fewer items when distraction was present at study. Also, the main effect of control was significant, $F(1,27)=7.59, M S E=.003, p=.01$, $\eta_{p}=.219$, as participants predicted they would remember more words when they controlled their study times. However, most importantly, the interaction was not significant, $F<1$, once again showing that monitoring was accurate whether metacognitive was allowed or precluded. A planned comparison of mean study times in the condition of participants' control over study times yielded a significant effect, $t(28)=5.58, S E=.06, p<.001, d=1.03$.

A 2 (distraction) $\times 2$ (control) within-participants ANOVA on correct recall yielded a significant main effect of distraction, $F(1,28)=78.54, M S E=.003, p<.001, \eta_{p}{ }^{2}=.737$, demonstrating that distraction impaired memory performance. The main effect of control was not significant, $F(1$,

\footnotetext{
${ }^{1}$ One participant was eliminated from this analysis for failure to provide aggregate JOLs for any of the study lists.
} 
$28)=2.91, M S E=.007, p=.099, \eta_{p}=.094$. The interaction was not significant, $F<1$. Thus, although participants predicted they would remember more words from lists in which they controlled their study times, this prediction was not borne out in the recall results. Similarly to Experiment 2, control over study times failed to benefit memory performance even under the optimal quiet conditions. Notably, in the present experiment when participants controlled their study times in the quiet condition each word was presented for the average of $2.95 \mathrm{~s}$, which is almost identical to study times observed in Experiment 1 and thus to the 3 second rate of presentation set in the comparison condition.

Experiment 4

A 2 (distraction) $\times 2$ (control) within-participants ANOVA on the means of aggregate JOLs yielded a significant main effect of distraction, $F(1,29)=42.73, M S E=.004, p<.001, \eta_{p}{ }^{2}=.596$, again demonstrating participants' awareness of the negative impact of auditory distraction on memory performance. There was no main effect of control, $F<1$, but a significant interaction was observed, $F(1,29)=8.15$, MSE $=.002, p=.008, \eta_{p}{ }^{2}=.219$. Participants predicted a larger effect of auditory distraction when they had control over study times, compared to a condition in which study times were set by an experimenter, although the effect observed when control was precluded was still reliable, $t(29)=4.77, S E=.01, p<.001, d=0.87$. The analysis of mean study times in the condition of participants' control over study times yielded a significant effect, $t(29)=4.52, S E=.12, p$ $<.001, d=0.82$, again replicating the effect of curtailing study under distraction.

A 2 (distraction) $\times 2$ (control) within-participants ANOVA on correct recall scores yielded a significant main effect of distraction, $F(1,29)=35.34, M S E=.007, p<.001, \eta_{p}{ }^{2}=.549$, testifying to a robust effect of auditory distraction on memory performance. The main effect of control was not significant, $F(1,29)=1.59, p>.21$, but there was a significant interaction, $F(1,29)=6.38, M S E=.003$, $p=.017, \eta_{\mathrm{p}}{ }^{2}=.180$. Further analyses revealed that when no distraction was present the condition where participants controlled study times outperformed the condition in which study time was set 
by the experimenter, $t(29)=2.24, S E=.02, p=.033, d=0.41$. This observation of benefits of selfregulation under favorable environmental conditions, surprisingly absent from Experiments 2 and 3 , conceptually is consistent with previous research (de Jonge et al., 2015; Mazzoni \& Cornoldi, 1993; Tullis \& Benjamin, 2011). Crucially, the benefits of exerting metacognitive control were no longer present under increased environmental demands of auditory distraction, $t<1$. This indicates that the environmental demands posed in a memory task set a limit on the effectiveness of selfregulation of study. Independent analyses of the effects of applying auditory distraction at encoding revealed that the distraction effect was present both when participants were given metacognitive control over their study times, $t(29)=5.90, S E=.02, p<.001, d=1.08$, and when control was limited by experimenter-set study times, $t(29)=3.79, S E=.02, p=.001, d=0.70$.

In addition to replicating both the effect of curtailing study under more challenging environmental conditions and the effect of distraction on metacognitive monitoring, the results of Experiment 4 suggest that more metacognitive control in a memory task may produce a counterintuitive result of a more pronounced memory impairment under conditions of increased environmental demands. The reason for this exaggerated impairment appears to be twofold. First, participants curtailed study when distraction was present. Second, the lack of effective compensatory strategies meant that participants' performance under increased environmental demand did not benefit from self-regulation. When contrasted with the benefit observed when environmental demand was reduced in the quiet condition, this resulted in a larger negative effect of auditory distraction when participants controlled study times in Experiment 4, although this pattern was absent from Experiments 2 and 3, an issue we soon address.

It is important to note here that the curtailing of study time under distraction did not lead directly to worsening of performance as compared to a control condition in which study times were set by the experimenter. Although when engaging in self-regulation, participants studied words on average for $2.59 \mathrm{~s}$ and thus for shorter than 3 seconds set in the comparison condition, performance 
was virtually identical across these conditions. One may thus argue that the participant-control condition reflects greater effectiveness of learning because the same level of memory performance was obtained with shorter study times. Lengthening study times might therefore lead only to a labor-in-vain type of effect where increments of study time are not associated with benefits to memory performance (Nelson \& Leonesio, 1988). Again, the exaggerated effect of auditory distraction when participant engage in self-regulation stems from the failure to benefit from selfregulation when environmental conditions become more demanding, and not directly from the worsening of performance due to shortening of study time.

One inconsistency in the present results is that no interaction of the level of metacognitive control and the presence of auditory distraction for memory performance was found in Experiments 2 and 3. There are two ways in which the discrepancy between Experiment 4 on the one hand and Experiments 2 and 3 on the other can be resolved. The first is to note that the performance effects obtained in Experiment 4 are relatively small and may not be detected in every experiment. In Experiments 2 and 3 we failed to observe an effect of manipulating metacognitive control under quiet, non-distracting conditions, which renders moot the question of benefits of control under distracting conditions. In essence, these two experiments did not provide the opportunity to examine the potential interaction when benefits of self-regulated study are present in the quiet condition. These two experiments are reported to avoid the file-drawer problem and provide contextual information on the replicability these effects (c.f., Pashler \& Wagenmakers, 2012). Thus, these experiments alert the reader that the pattern observed in Experiment 4 requires additional scrutiny, which is provided, with greater statistical power, in Experiment 5.

The second way to reconcile the results of experiments presented thus far is to query the difference between recalling categorized and uncategorized words. The recall process for these experiments may differ in the relative contributions of serial order information. Recall of categorized words - used in both Experiments 2 and 3 - is driven by semantic reconstruction, thus making serial 
order information potentially less important (Polyn, Norman \& Kahana, 2009), whereas recall of uncategorized words - used in Experiment 4 - is predominantly driven by items' temporal proximity within a list and retrieval of serial order information (Raaijmakers \& Shiffrin, 1981; Tan \& Ward, 2007), variables which remain important even if free recall instructions are given (Beaman \& Jones, 1998; Beaman \& Morton, 2000; Grenfell-Essam \& Ward, 2012; Grenfell-Essam, Ward, \& Tan, 2013; Ward, Tan \& Grenfell-Essam, 2010). It is possible that self-regulated study under favorable environmental conditions is particularly beneficial for creating inter-item associations that can later benefit retrieval of serial order information and thus free recall of uncategorized words. If this is the case, then one might predict effective self-regulation under favorable environmental conditions for uncategorized words in Experiment 4 but not for the categorized words used in Experiments 2 and 3. This would also suggest that the improvements brought about by more self-regulation under favorable conditions, and the pattern of increased costs of more challenging environmental conditions under self-regulated study, are phenomena arising from specific conditions which encourage the use of inter-item associations, such as free recall testing of unrelated words. Rote rehearsal is expected when free recalling unrelated words - as shown by numerous studies of overt rehearsal (e.g., Grenfell-Essam \& Ward, 2012; Grenfell-Essam et al., 2013; Tan \& Ward, 2000) but related items might provoke different strategies which would give rise to a different pattern of results. Experiment 5 included a condition that aimed at assessing this hypothesis.

\section{Experiment 5}

Experiment 5 used the basic design of Experiments 2-4, manipulating the presence of distraction and the locus of control over study times. The primary purpose of Experiment 5 was to provide additional test of how effective self-regulated study is in the quiet and distraction condition. To this aim, more participants were recruited in Experiment 5. Additionally, in Experiment 5 we also manipulated the nature of the recall tests participants were required to complete. All studied lists included uncategorized words, as in Experiment 4. In one condition, participants were asked to 
freely recall studied words, as in Experiments 2-4. In the other condition, participants were given stems of studied words as cues for recall. These stems were provided in a random order, thus minimizing the role of item-order information for memory performance. This condition constitutes thus a test of the generalizability of our findings beyond testing conditions relying heavily on interitem associations.

\section{Method}

Participants. Fifty-six undergraduates from Cardiff University participated in the experiment for course credit or small monetary compensation. Power analysis indicated that fifty-one participants would be sufficient to obtain power of .85 given a small-to-medium effect size of $\eta_{p}{ }^{2}=$ .02 and a moderate correlation between repeated measures of $r=.50$.

Materials and design. A new set of 600 words was chosen from the MRC linguistic database. These words were sorted into 40 lists of 15 words. Within a single list no two words started with the same two-letter stem. The design of the experiment was a 2 (distraction: present vs. absent) $\times 2$ (control over study times: participant vs. experimenter) $\times 2$ (type of recall test: free recall vs. stemcued recall) factorial with all factors manipulated within participants. The control factor was manipulated between two blocks of 20 lists with the order of the blocks counterbalanced across participants. The distraction and type of recall test were manipulated between lists but within blocks.

Procedure. The procedure for the free recall condition was the same as the procedure for Experiment 4, except that the JOL question was no longer asked after study and thus the procedure moved directly to a recall phase. All previous experiments provided unequivocal evidence that JOLs are lowered under conditions of auditory distraction and hence JOL prompts were omitted in order to simplify the experimental procedure. For the stem-cued recall test participants were presented with the first two letters of each of the studied words in a random order and they were asked to 
type in a studied word which matched the stem. The time for each test trial was not limited and participants needed to press Enter in order to move to the next stem cue or terminate the test.

\section{Results and discussion}

The descriptive statistics can be found in Table 1 (recall data) and Table 2 (study time data). We first assessed whether the finding of curtailed study times under auditory distraction was replicated in the present experiment. A 2 (distraction: present vs. absent) $\times 2$ (type of recall test: free recall vs. stem-cued recall) within-participants ANOVA on the mean of study times in the selfregulated condition confirmed the predicted effect of distraction, $F(1,55)=42.25, M S E=0.28, p<$ $.001, \eta_{p}^{2}=.434$, replicating the effect of curtailing study observed in all previous experiments in the present study. Unsurprisingly, given that type of test was manipulated after study times were collected, neither the main effect of type of test, $F(1,55)=1.78, p>.18$, nor the interaction, $F<1$, were significant.

The analysis of correct recall proportions was conducted with a 2 (distraction) $\times 2$ (control: participant vs. experimenter) $\times 2$ (type of recall test) within-participants ANOVA. This yielded a significant main effect of distraction, $F(1,55)=104.42, M S E=.007, p<.001, \eta_{p}{ }^{2}=.655$, showing the predicted impairment of memory performance under auditory distraction. The main effect of control was significant, $F(1,55)=7.11, M S E=.029, p=.010, \eta_{p}{ }^{2}=.114$, showing that participants' memory performance generally benefitted if participants were given control over their study times. The only other significant effect was an interaction between distraction and control, $F(1,55)=4.27$, MSE $=.006, p=.043, \eta_{\mathrm{p}}^{2}=.072$, showing again two things. First, self-regulated study enhanced memory performance under quiet, no-distraction conditions, $t(55)=3.17, S E=.02, p=.002, d=0.43$ (collapsing across type of recall test), but not under more challenging learning conditions of auditory distraction, $t(55)=1.61, S E=.02, p>.11$. Second, the negative effect of auditory distraction on memory performance was reliable both when participants were free to self-regulate their study, $t(55)=8.34, S E=.01, p<.001, d=1.11$, and when study times were controlled by the experimenter, 
$t(55)=6.69, S E=.01, p<.001, d=0.90$. Thus the interaction reflects an exaggerated impact of auditory distraction when participants are given control over study times (see Table 1). Crucially, the triple interaction of distraction, control and type of recall test was not significant, $F<1$, indicating that the type of recall test did not modulate the aforementioned effects.

The results of the present experiment confirm our conclusions regarding metacognitive control under auditory distraction, while providing additional insights into the impact of selfregulation on memory performance. First, as in all previous experiments, participants did not try to compensate for increased environmental demands during encoding by extending study time and instead they curtailed study under distraction. Second, participants' ability to enhance memory performance through self-regulated study was limited to the quiet condition and self-regulated study failed to confer benefits for performance when environmental demands increased. At the same time, speeding up under distraction generally did not impair performance as compared to the control condition in which study times were set by the experimenter. Third, as a consequence, memory impairment caused by auditory distraction was actually larger when participants engaged in self-regulated study. All these effects emerged independently of the final test used. Whether this test was free recall, depending on inter-item associations, or cued recall, independent of memory for such associations, there were clear limits to the benefits conferred by self-regulated study.

The present results are consistent with the pattern obtained in Experiment 4 and suggest that any potential difference between conditions utilizing categorized (Experiments 2-3) and uncategorized words (Experiment 4) does not lie in the use of inter-item associations for uncategorized words. With sufficient statistical power - as provided in Experiment 5 - an interactive pattern suggestive of exaggerated distraction-induced impairment with allowed control over study times is supported. We thus refrain from a further discussion of differences in the interaction of distraction and self-regulated vs. imposed study time obtained across experiments, suggesting only 
that such differences may reflect a sampling error successfully eliminated in Experiment 5 by using a greater sample size.

This issue aside, the results of our experiments have otherwise been remarkably consistent and provide answers to our primary questions regarding self-regulated study under distraction. We know now that participants are aware of the negative impact of auditory distraction on memory performance, as evidenced by a consistent pattern of lowered aggregate JOLs for lists studied in noise in Experiments 1-4. These results join the previous observation from item JOLs (Hanczakowski et al., 2017) in showing accurate metacognitive monitoring of auditory distraction. We also know that distraction has a counterintuitive effect on study times. In all experiments presented here, participants curtailed study when learning was impeded by the presence of distraction. This remains in contrast to the observation derived from studies manipulating item difficulty by which people are generally inclined to devote more study time when learning becomes more difficult (e.g., Thiede \& Dunlosky, 1999; Tullis \& Benjamin, 2011). Finally, we know that self-regulated study does not produce the benefits to memory when environmental demands (represented by auditory distraction) are increased, which contrasts with small but reliable benefits observed in Experiments 4 and 5 when self-regulation was employed in the quiet condition.

The result concerning study times is of particular interest here as a novel observation of how metacognitive control becomes decoupled from accurate metacognitive monitoring. However, given the novelty of this result, the exact reason for which people curtail study under distraction is not yet clear. Experiments 6-8 are thus devoted to elucidating the reasons why study times are curtailed under distraction. These experiments build on a distinction between two components of metacognitive control over learning. As shown by Ariel and his colleagues (Ariel, Al-Harthy, Was, \& Dunlosky, 2011; Ariel \& Dunlosky, 2013; Dunlosky \& Ariel, 2011b), learning is shaped both by strategic considerations, such as decisions to study for longer those items one particularly wants to remember, and on habitual processes capable of overriding such learning agendas, at least to some 
extent. For example, one can strive to devote more study time to more important items while at the same time still prioritizing items for study in the reading order of one's native language (e.g., leftright for English, right-left for Arabic; Ariel et al., 2011). If a distinction between strategic and nonstrategic components of learning is adopted, then the question is which of these components is responsible for study curtailment under distraction.

One of the most prominent models of study time allocation which distinguishes between stimulus-driven and strategic components of learning is the discrepancy reduction model (Dunlosky \& Thiede, 1998) The strategic component of this model is referred to as a norm of study, which relates to an overall goal set for the process of learning. When people engage in study, they strive to reduce the discrepancy between the current state of learning for a given item and the norm of study. Because the current state of learning for more difficult items is by definition poorer than for easier items, it takes longer to reduce this discrepancy and reach the norm of study, giving rise to the usual negative JOL-study time relationship. However, the norm of study allows for different types of difficulty-study times relationship if people adopt different norms of study under different conditions. When norm of study is lower in a given condition, this should be reflected in both lower predicted performance and the shorter study-time needed to reduce the discrepancy between current state of learning and the lower goal.

To account for the current results, the strategic account of study curtailment evoking the concept of the norm of study needs to assume that the norm of study is lower when study is accompanied under auditory distraction. Participants would then reduce the discrepancy between this lowered norm of study and the current state of learning for words in the distraction lists more quickly than for control lists, resulting in the observed pattern of curtailing study under auditory distraction. Adopting a lower norm of study for lists accompanied by auditory distraction is a strategic decision which might be arrived at for a number of reasons. Although distracters were played at an intensity commensurate with normal, everyday speech (to which participants should be 
generally accustomed), it is possible that participants disliked hearing continuous speech presented over headphones and were prepared to accept lower memory scores in these conditions if the alternative meant studying for longer. Alternatively, participants may similarly reason that longer study under distraction necessarily means longer exposure to auditory distraction and consequently infer that gains due to extended study would be obliterated by increased exposure (e.g., Bridges \& Jones, 1996).

There are two ways to test the strategic account of why people curtail study under distraction. First, one could strive to equate the norms of study across quiet and distraction conditions to see whether this would eliminate the effect. However, this is not without its problems because there is no method for measuring participant's norm of study - a theoretical construct which is not directly observable - and thus no way to assess whether incentives are capable of equating norms across conditions. Second, one could decouple study times from the norm of study. If study times are no longer strategically controlled in service of memory performance, then any differences between norms adopted under distraction and control conditions should have no bearing on study time allocation, hence study curtailment should be eliminated. In Experiment 6 we pursued this route by changing experimental instructions and asking participants to control the study presentation so that each word would be displayed for the same, specific duration. In this way, study times should no longer be shaped by performance goals but by a more immediate goal of pacing presentations according to experimental instructions, rendering norms of study irrelevant and potentially eliminating the effect.

\section{Experiment 6}

In the present experiment, participants were again asked to study lists of words in quiet or under auditory distraction for subsequent recall. Participants controlled the rate of presentation of study words in the same way they did in participant-control conditions of Experiments 1-5. The study instructions were however changed and in the present experiment participants were explicitly 
asked to terminate the presentation of each of the study word after three seconds elapsed. If the effect of curtailing study time is caused by strategic considerations on the part of the learners, then instructing them directly to equate study time between experimental conditions should eliminate the effect.

Participants. Twenty-one undergraduates from Cardiff University participated in the experiment for course credit. The smaller sample size in this experiment, as compared to Experiment 5 , reflects its focus on study times - a very robust effect in all previous experiments - rather than more elusive changes to recall patterns. Power analysis revealed that seventeen participants should be sufficient to obtain power of. 85 to detect a large effect of $d=0.8$.

Materials, design, and procedure. The materials for the present experiment were taken from Experiment 1 and consisted of 10 categorized lists of words. Half of these lists were studied in quiet and half were accompanied by auditory distraction that was taken from previous experiments. As in Experiment 5, the JOL prompt was again omitted to simplify the procedure, which was focused on study time allocation rather than monitoring. Participants controlled the study presentations for all lists. They were instructed to control the presentations in such a way as to ensure that each study word was presented on the screen for three seconds. They were also instructed to remember the words for free recall tests following each list and it was stressed that memorizing and recalling words was the main task on which they should concentrate. Training sessions were included in the procedure so as to ensure that participants had prior experience of an interval of three seconds in this context. The procedure started with an additional training list of 15 words from a single category presented for both study and immediate free recall which was not scored. In this training list, participants were provided with an error feedback for any word that was presented on the screen for shorter than $2700 \mathrm{~ms}$ or longer than $3300 \mathrm{~ms}$. In the procedure proper, additional training blocks were included after every two study lists. Each training block consisted with a single word 'Training' being displayed 10 times, again with the instructions for participants to control the presentation so 
that the word would be displayed for three seconds and with feedback for too short or too long displays.

\section{Results and discussion}

The descriptive statistics can be found in Table 1 (recall data) and Table 2 (study time data). A $t$ test comparing correct recall across quiet and distraction conditions yielded a significant difference, $t(20)=4.69, S E=.02, p<.001, d=1.03$, confirming the disruptive effect of distraction on memory performance. Of main interest, however, remain the average study times which also differed across conditions, $t(20)=7.96, S E=.05, p<.001, d=1.74$. Thus, even when participants were clearly instructed that the study words should be presented for the same duration across quiet and distraction lists, they still curtailed study when it was accompanied by auditory distraction. These results are inconsistent with the strategic account of study time curtailment. Given that in the present experiment participants controlled presentation times in service of meeting a goal of keeping constant display duration rather than in service of memory performance, differences in study times across conditions are not accounted for by strategic considerations regarding performance goals.

If the strategic account is dismissed, what kind of basic cognitive process - other than memory itself - might be affected by auditory distraction? The procedure used in Experiment 6, which asked participants to study words for a certain, experimenter-defined duration, resembles the procedures commonly used in research on time perception. In temporal production tasks, participants are given a specific time interval after which they need to terminate the presentation of a stimulus (cf. Matthews \& Meck, 2016; Mioni, Stablum, McClintock, \& Grondin, 2014), just as they were asked to terminate the presentation of study items after three seconds in Experiment 6, with shorter termination times indicating that a given interval is perceived subjectively to last longer. The similarity of the procedure of Experiment 6 to this paradigm suggests that auditory distraction could alter time perception in such a way that participants exaggerate the time they devote to studying 
items when accompanied by continuous speech. Indeed, research on time perception has consistently found that the perceived duration of a certain interval depends on the amount of change to stimuli occurring during this interval (e.g., Brown, 1995). Auditory distraction used here consisted of words spoken at the rate of $750 \mathrm{~ms}$ which meant that during the average length for which study word was presented - about three seconds across experiments - participants heard about four spoken words, thus experiencing multiple changes of auditory stimuli. The prediction following from the time perception studies is thus that duration for which words are studied under distraction should seem longer than duration for which words are studied in the quiet condition. Consequently, given freedom to allocate study time, participants should spend less time studying under distraction, the pattern of results consistently observed across experiments presented here.

The clear prediction of the time perception hypothesis is that the effects of auditory distraction on time allocation should not be limited to memory tasks. Given the low-level and fundamental nature of the time perception mechanism, its effect should be detected across various tasks requiring participants to allocate time, including tasks that are used in the time perception studies. A straightforward test of the time perception hypothesis would be thus to examine the effect of auditory distraction in the basic temporal production task without a memory component. If auditory distraction alters time perception, then it should lead to the same effect of curtailment of an interval even when participants are not required to learn study words. To establish whether auditory distraction of the type employed here affects the perception of the timing of stimuli presentation beyond memory tasks, in Experiment 7 the memory component was removed and participants were only asked to control the rate of the presentation of a simple stimulus in the form of a black dot.

\section{Experiment 7}

The present experiment used a temporal production paradigm in which participants were presented with a simple perceptual stimulus - a black dot - the presentation of which they were 
asked to terminate after three seconds. This simple task was performed either in quiet or with auditory distraction. If auditory distraction alters time perception in such a way as to make time intervals seem to last longer, we predict shorter termination times under auditory distraction, paralleling the effect of shorten study times documented in Experiments 1-6.

Participants. Twenty-three undergraduates from Cardiff University participated in the experiment for course credit.

Materials, design, and procedure. The structure of the present experiment were the same as Experiment 6 but all study words were substituted with a black dot of the diameter of about $3 \mathrm{~cm}$ that was centered on the computer screen and recall tests were dropped from the procedure. Thus, the dot was presented in runs of 15 displays that were either presented in quiet or with accompanying auditory distraction which was the same as in Experiments 1-6. Participants were asked to control the presentation of the dot by pressing spacebar when three seconds elapsed. The procedure started with a training run of 15 displays which were accompanied by feedback. Additionally, training sessions with feedback for the word 'Training' were included every two runs of the dot task.

\section{Results and discussion}

The only dependent measure for this experiment was the average time for which the dot was displayed. The descriptive statistics can be found in Table 2. A $t$ test comparing quiet and distraction conditions yielded a significant difference, $t(22)=5.98, S E=.04, p<.001, d=1.25$. Thus, even in a task without a memory component, participants curtailed presentation times under conditions of auditory distraction.

The fact that auditory distraction affects performance in the time production task without any memory component indicates that the main locus of the distraction effect is on subjectively perceived duration of a time interval. When speech is present, participants seem to perceive the 
interval as lasting longer and hence they are prone to terminate the presentation of a stimulus early. This effect most likely occurs because participants judge the duration based on the number of individual events occurring within a given interval. Since judgments of interval duration depend largely on the amount of environmental change occurring within a given interval (cf. Brown, 1995; Kanai, Paffen, Hogendoorn, \& Verstraten, 2006), intervals filled with changing distracters seem to last longer than unfilled intervals. The use of continuous speech in the present series of experiments means that in the auditory distraction conditions participants are exposed to numerous auditory tokens - essentially environmental changes - which contrasts with the lack of environmental changes in the quiet conditions.

The present results confirm that the effect of shortening study under auditory distraction observed in Experiments 1-6 is not due to participants' strategic considerations but instead it is a stimulus-driven effect that generalizes across memory and non-memory tasks. The strategic account clearly requires a memory task in which study times are curtailed under distraction in order to realize goals in terms of memory performance. No such goals exist in a non-memory task and thus, in order to be viable, the strategic account would need to propose that speeding up in the memory task is due to control participants exercise in service of memory performance and the same effect in the non-memory task is due to a different, unrelated mechanism. This account thus clearly lacks parsimony, in contrast to the time perception hypothesis that straightforwardly assigns speeding-up across different cognitive tasks to the same underlying mechanism. Thus, the present results underscore the fact that what might seem as higher-order strategic choices examined from the metacognitive perspective may in fact be a function of more fundamental cognitive processes underlying performance across a wide spectrum of cognitive endeavors. As previously argued by Ariel and colleagues (e.g., Ariel, Al-Harthy, Was, \& Dunlosky, 2011; Ariel \& Dunlosky, 2013; Dunlosky \& Ariel, 2011b), study times which were discussed throughout Experiments 1-6 as reflecting strategic choice may be in fact not only the function of how people wish to pursue their agendas but also a 
function of habits or, as in our case, simple illusions created by the core features of our cognitive system.

The time perception account of study curtailment suggests, however, that study time is curtailed because distraction directly influences participants' assessments of how long they have spent on appropriate processing - such as encoding and maintenance rehearsal - during study. The generality of this effect is thus not yet clear. It appears in simple time production (Experiment 7), attempts to match study time to a given target (Experiment 6), and in learning of semantically related (Experiments 1-3) and unrelated words (Experiments 4-5). Thus, at first blush, the effect appears widespread across multiple stimuli, situations and types of task. However, one should note that all memory tasks examined in the present study afforded little strategic control over learning beyond control over presentation times. In memory tasks examined here, participants were presented with individual words, which are commonly studied via rote rehearsal strategy. In this case, participants can exert control over their study chiefly by allocating varying amount of time to different items. When strategic control over study is exerted by overtly controlling study time, stimulus-driven effects distorting the process of study time allocation - such as alterations in time perception - are likely to play a major role. However, if strategic control can be realized by using learning strategies beyond study time allocation, the role of stimulus-driven effects on study time allocation should be diminished. This prediction was examined in Experiment 8, in which the pairedassociates task was used. Pairs of words when used as study materials support strategic learning that goes beyond decisions regarding how long each pair of words should be presented. Studies have found that when presented with pairs of words to learn, participants strive to find a mediator a picture, a sentence, a semantic associate - that links two words in a given pair (e.g., Richardson, 1998). Thus, control over study is exerted less by deciding for how long a given pair should be rehearsed, and more by the process of searching for effective mediators, with pairs affording accessible mediators studied for shorter periods than pairs for which finding mediators is more difficult. With a reduced role for time per se in strategic decisions about the learning of pairs of 
words, distortions in perception of study time should no longer play a major role in study time allocation. Rather, study time will be a consequence of the time needed to find an effective mediator. We have no a priori reason to suppose that this will be directy affected by auditory distraction, and certainly not in the direction of curtailing study time by aiding such a search.

\section{Experiment 8}

The present experiment assessed the generalizability of the effect of curtailing study under auditory distraction to a memory task using pairs of unrelated words as study materials. We assume here that the encoding strategy for self-regulated learning of pairs of words is not dependent on assessing how much time is spent per item on rote rehearsal, relying instead on more elaborative strategy of linking two words via a common mediator. Although the process of finding mediators is likely to be time-dependent, time elapsed during study is not itself used as the basis for exercising strategic control over study, rather it is simply a by-product of the process of searching for mediators. We predict that when strategic control is no longer exercised via study time allocation, distortions in time perception will not affect the duration of study as success in mediator search, rather than time spent on study, is used to assess study effectiveness. Thus, we predict no effect - or at least a substantially reduced effect - of auditory distraction on study time when pairs of words are used as study materials.

Participants. Thirty-four undergraduates from Cardiff University participated in the experiment for course credit. Previous experiments reported in the present study documented a large effect of distraction on study times (average $d=.9$ ). The power to detect a large effect of $d=$ 0.80 (as defined by Cohen, 1988) with the current sample size was .994.

Materials, design, and procedure. Two hundred and forty nouns were chosen from the MRC psycholinguistic database. They were randomly divided into cue-target pairs which were then randomly divided into eight lists of 15 pairs each. These pairs of words were presented for study in the quiet and distraction conditions. Auditory distraction was the same as in all previous 
experiments from this series. Participants were asked to memorize the pairs while ignoring auditory distraction (if present), provide aggregate JOLs - the assessments of the number of targets they would be likely to recall - after each study list and provide answers in cued recall tests administered immediately after each study list. In the cued recall tests, cues were presented individually and participants had up to 10 seconds to type in a target associated with a given cue.

\section{Results and discussion}

The descriptive statistics can be found in Table 1 (recall and JOL data) and Table 2 (study time data). A $t$ test comparing cued recall performance across quiet and auditory distraction conditions yielded a significant difference, $t(33)=2.43, S E=.01, p=.021, d=0.36$, confirming the harmful effect auditory distraction at encoding has on subsequent memory performance. A $t$ test comparing the means of aggregate JOLs also yielded a significant difference, $t(33)=5.72, S E=.01, p$ $<.001, d=0.95$, once more confirming that metamemory monitoring is sensitive to the effect of auditory distraction on memory performance. However, in contrast to all experiments included in the present series, a comparison of mean study times across quiet and distraction conditions was not significant, $t(33)=1.21, p>.23$. Thus, even though the effect of curtailing presentation times is robust enough to generalize across memory and non-memory tasks (see Experiment 7), there are still limits to the effect as it does not appear to affect study times in the paired-associates task. This null result is consistent with the idea that the strategies deployed in paired-associate learning should not be affected by altered time perception - the apparent locus of the effect of curtailing study under auditory distraction - or, at least, are not affected to the same degree.

The null result observed here puts important limits on generalizability of the present findings across learning conditions. We started the present investigation by examining single words, following the traditional paradigms used in the literature on auditory distraction. Studies on metacognitive aspects of learning more frequently use pairs of words as study materials. One could argue, from a practical standpoint, that pairs of words might be more appropriate methodologically 
since students may be more likely to engage in elaborative rather than rote rehearsal in real-life scenarios. However, although this may be the case, it is itself an empirical question. Rote rehearsala process common in free recall tests and sensitive to distraction-induced distortion in time perception - is likely to be involved in various learning situations, either due to personal characteristics (e.g., limited working memory capacity) of some learners who do not employ more effective learning strategies (e.g., Unsworth, 2016) or the nature of the study materials that may not be open to elaborate processing, such as in the case of learning foreign language vocabulary (Baddeley, Gathercole \& Papagno, 1998).

\section{General Discussion}

Learning is a process that is likely to take place not only in the quiet library but often in the noisy common room or dormitory. The studies on how people approach the learning task have so far been focused on the 'quiet library' scenario where people are free to regulate learning under optimal environmental conditions. These studies by and large suggest that learning benefits from exerting metacognitive control because people are capable of assessing the effectiveness of the learning process - the monitoring component - and adjust learning strategies accordingly - the control component. In the present study, we proposed a new perspective on learning by examining strategic aspects of the learning process - monitoring, control and their joint effects on performance - as unfolding not in an optimal environment but under conditions akin to the 'noisy dormitory' scenario. Our results indicate that the regularities of strategic learning described for optimal environments may not generalize to noisy environments, with important consequences for the ultimate results of the learning process. We postulate that the differences between learning in optimal and noisy environments have deep underlying causes grounded in basic cognitive processes that, when altered by the presence of noise, have cascading effects on higher-order strategic regulation of learning. 
Across all experiments presented here, learning was consistently less effective under conditions of auditory distraction, resulting in reduced subsequent memory performance. Of primary interest were the effects of the environmental demand manipulation on metacognitive monitoring, metacognitive control and the effectiveness of self-regulatory processes. Only if there is awareness of the impact of experimental manipulations on performance can control operations be modified to meet changing demands. Five experiments $(1-4,8)$ demonstrated that participants were aware of increased demands posed by auditory distraction, factoring these demands into their predictions of subsequent memory performance. Aggregate JOLs were always lower when auditory distraction accompanied study. This result remains consistent with our previous observation that auditory distraction is correctly factored into item JOLs (Hanczakowski et al., 2017), again indicating accurate metacognitive monitoring of auditory distraction.

In the present study we also looked at metacognitive control in terms of participants' decisions when to terminate study of a given item. Previous research has considered this form of metacognitive control as function of either objective or perceived difficulty of the study materials. As described by the discrepancy-reduction model (Dunlosky \& Thiede, 1998; Thiede \& Dunlosky, 1999), participants devote more study time to items that are deemed more difficult to learn and are thus assigned lower JOLs. This negative relationship between JOLs and study times is found generally when participants have ample time to study given material and try to master as much of it as possible. Given that in the present study we did not limit the overall time available to participants, we could have expected their behavior to follow the discrepancy-reduction model, with longer study times in conditions characterized by lower JOLs. In fact we found the opposite pattern, as participants curtailed study when external demands of the task were increased by applying auditory distraction. Whereas people are often willing to devote more time to materials that are more challenging to learn, they are also clearly less inclined to devote time when study conditions become more challenging. 
One way to account for our findings is by assuming that the learning agenda differs across conditions of varying environmental demands. For example, if people realize that learning becomes less effective in more challenging environmental conditions, and our monitoring results suggest that they do, they may set lower expectations for how much material can and should be mastered under such challenging conditions. Meeting these lower expectations would require less effort, resulting in an altered relation between metacognitive monitoring and the allocation of study time. This account is, however, not without difficulties. It could explain our main experimental finding - the curtailment of study under more challenging environmental conditions - but it does not sit well with other findings from our study. Specifically, we found the effect of curtailing presentations under auditory distraction to be general across cognitive tasks, affecting not only study under self-regulation instructions but also study in the task in which participants are explicitly asked to equate presentation times across quiet and distraction conditions (Experiment 6) and presentation times in a non-memory task of temporal production (Experiment 7), results difficult to accommodate within the strategic frameworks. We also found that the robust pattern of study curtailment under distraction observed for single words can be eliminated when materials are changed to pairs of words (Experiment 8). We argue that this last result is not straightforwardly predicted by a hypothesis evoking strategic control as a mechanism of study curtailment under distraction. If participants accept lower levels of performance under distraction, then learning pairs of words should be subjected to such a lowered norm of study, in a similar manner to individual words in Experiments 1-6. Arguably, learning pairs of words is not directly dependent on study time, but rather on creating mediators between words. Creating mediators is also a time-dependent process so less effort invested in learning pairs of words under distraction should translate into shorter time spent on creating mediators, indirectly affecting study times. However, such study curtailment was not observed. Altogether, these results, although they do not necessarily rule out the possibility of different goals or norms of study across conditions varying in environmental demands, nevertheless make this account of study curtailment less than parsimonious. 
Our preferred account is one in which distraction-induced changes to study times are not mediated by any strategic considerations. According to the time perception account, auditory distraction in the form of continuous speech affects the way participants perceive the temporal duration of intervals, with intervals filled with spoken words lasting subjectively longer than unfilled intervals. The idea that auditory distraction may affect time perception is in agreement with theories of time perception which assume that the amount of environmental change in a certain interval determine how long this interval is perceived to be (Brown, 1995). This account makes a specific prediction that the effect of curtailing study would obtain only in tasks in which the self-regulation of learning strategy is based upon a judgment of processing of time, for example rehearsal of study elements which participants control by devoting a certain amount of time for each item. In tasks for which other strategies are available, there is no reason to expect curtailment, a prediction supported by the results of Experiment 8, showing that the curtailment, robustly present in all experiments involving learning of single words, is absent in the paired-associate task.

The time perception account, although nicely fitting all results presented in the current study, clearly needs additional work, both from the perspective of the role of auditory distraction on time perception in various tasks like prospective and retrospective duration judgment paradigms (cf. Block, Hancock, \& Zakay, 2010) and from the perspective of its role in memory tasks. Regarding distraction, all our experiments used the same type of distraction, namely spoken individual words. Such distraction has been commonly used in laboratory experiments and repeated comparisons with more ecologically valid distraction (e.g., natural speech; see reviews by Banbury et al., 2001; Beaman, 2005; Hughes \& Jones, 2003; Jones et al., 2010) do not find any difference in the effects of, for example, rhythmic vs. irregular presentation of speech (Parmentier \& Beaman, 2015). Thus, we expect our results to generalize beyond the particular auditory (speech) stimuli and presentation conditions utilized here. Nevertheless, further empirical work is required to look at metacognitive effects elicited by a broader range of types of noise. From the applied perspective, of particular 
importance remains the effect of background music, since - other than speech itself - this type of noise is perhaps most likely to accompany deliberate learning.

Our results also have implications for other aspects of the metacognitive framework. Several studies have found that people given control over study times outperform those for whom study times are set by the experimenter (de Jonge et al., 2015; Mazzoni \& Cornoldi, 1993; Tullis \& Benjamin, 2011). Two experiments (Experiments 4-5) replicated this observation when study was not accompanied by auditory distraction, revealing the benefits of self-regulated study. However, these benefits were not robust across environmental conditions. Specifically, allowing metacognitive control over study times did not confer benefits to memory performance under auditory distraction. In consequence, the harmful effects of auditory distraction on performance were actually larger when self-regulation was allowed rather than precluded.

The exaggerated negative effect of challenging environmental conditions under selfregulation has important implications for our understanding of the effectiveness of learning. In our study, we operationalized varying environmental conditions as the presence or absence of auditory distraction, which follows a long tradition of investigating distraction effects on memory. Importantly, studies on auditory distraction have obvious applied implications that have been extensively examined in relation to various real-life settings ranging from offices (Banbury \& Berry, 1998) and lecture halls (Zeamer \& Fox Tree, 2013) to air-traffic control rooms (Tremblay, Parmentier, Hodgetts, Hughes, \& Jones, 2012). As a result of these investigations, several methods of reducing the impact of noise have been described, including pre-familiarization of distracting stimuli (Bell, Röer, Dentale, \& Buchner, 2012; Röer, Bell, \& Buchner, 2014), closing eyes (Perfect, Andrade, \& Eagan, 2011), masking the sound (Beaman \& Holt, 2007; Jones \& Macken, 1996) and perceptually degrading stimuli to promote task immersion (Halin, Marsh, Haga, Holmgren, \& Sörqvist, 2014; Hughes, Hurlstone, Marsh, Vachon, \& Jones, 2013; Marsh, Sörqvist, \& Hughes, 2015). Each of these manipulations, however, requires prior practice at the task (Bell et al., 2012; Röer et 
al., 2014), instruction of the participants (Perfect et al., 2011) or direct manipulation of the distracter (Beaman \& Holt, 2007; Jones \& Macken, 1996; Jones, Alford, Macken, Banbury, \& Tremblay, 2000) or the stimulus materials (Halin et al., 2014; Hughes et al., 2013; Marsh et al., 2015). Study-time choice does not require artificial control of the environment by an experimenter and is a strategy that is spontaneously adopted by participants without the need for prior exposure to the auditory environment. Given this, the unfortunate consequences of self-regulation for memory performance under conditions of auditory distraction suggest that this might be a common feature of any realworld tasks and environments in which time spent on task is used as a means of controlling study effectiveness.

Context of the Research

The present study was conceived as a project linking two diverse fields of investigation within cognitive psychology of memory: distraction effects and metacognitive regulation of learning. Our research group has long investigated auditory distraction, documenting its pervasive effects on memory performance across the variety of memory tasks, including a short-term memory task of serial recall and a long-term memory task of free recall. The robustness of distraction serves as the building block of the current theories of distraction, underscoring the obligatory nature of auditory processing. The idea that stood behind the present project was that perhaps higher-level processes can be recruited to compensate for the obligatory engagement of a cognitive system in processing irrelevant sound. The results, however, suggest that a change auditory distraction brings about to processing at the fundamental level of cognition has cascading effects at higher levels, undermining strategies that could be deployed to counter distraction. The present study looked at a single type of metacognitive strategy in the form of study time allocation. It is thus possible that other strategies can deployed in order to compensate for distraction effects. Indeed, a very recent study by Middlebrooks et al. (2017), published when we were preparing the present paper, shows how even under conditions of distraction people may still effectively prioritize important information for 
learning. We believe that a wide range of metacognitive strategies should be pursued in further empirical work, contributing to our understanding of memory in applied domains as well as illuminating the mechanisms of distraction effects on cognitive performance. 
References

Ariel, R. (2013). Learning what to learn: The effects of task experience on strategy shifts in the allocation of study time. Journal of Experimental Psychology: Learning, Memory, and Cognition, 39, 1697-1711.

Ariel, R., Al-Harthy, I. S., Was, C. A., \& Dunlosky, J. (2011). Habitual reading biases in the allocation of study time. Psychonomic Bulletin \& Review, 18, 1015-1021.

Ariel, R., \& Dunlosky, J. (2013). When do learners shift from habitual to agenda-based processes when selecting items for study. Memory \& Cognition, 41, 416-428.

Ariel, R., Dunlosky, J., \& Bailey, H. (2009). Agenda-based regulation of study time allocation: When agendas override item-based monitoring. Journal of Experimental Psychology: General, 138, 432-447.

Baddeley, A. D., Gathercole, S. E., \& Papagno, C. (1998). The phonological loop as a language learning device. Psychological Review, 105, 158-173.

Banbury, S., \& Berry, D. C. (1998). The disruption of office-related tasks by speech and office noise. British Journal of Psychology, 89, 499-517.

Banbury, S., Macken, W. J., Tremblay, S. \& Jones, D. M. (2001). Auditory distraction and short-term memory: Phenomena and practical applications. Human Factors, 43, 12-29.

Beaman, C. P. (2004). The irrelevant sound phenomenon revisited: What role for working memory capacity? Journal of Experimental Psychology: Learning, Memory, and Cognition, 30, 11061118.

Beaman, C. P. (2005). Auditory distraction for low-intensity noise: A review of the consequences for learning and workplace environments. Applied Cognitive Psychology, 19, 1041-1064. 
Beaman, C. P., Hanczakowski, M., Hodgetts, H. M., Marsh, J. E., \& Jones, D. M. (2013). Memory as discrimination: What distraction reveals. Memory \& Cognition, 41, 1238-1251.

Beaman, C. P., \& Holt, N. J. (2007). Reverberant auditory environments: The effect of multiple echoes on distraction by "irrelevant" speech. Applied Cognitive Psychology, 21, 1077-1090.

Beaman, C. P., \& Jones, D. M. (1998). Irrelevant sound disrupts order information in free recall as in serial recall. Quarterly Journal of Experimental Psychology, 51A, 615-636.

Beaman, C. P., \& Morton, J. (2000). The separate but related origins of the recency and the modality effect in free recall. Cognition, 77, B59-B65.

Bell, R., Röer, J. P., Dentale, S., \& Buchner, A. (2012). Habituation of the irrelevant sound effect: Evidence for an attentional theory of short-term memory disruption. Journal of Experimental Psychology: Learning, Memory, and Cognition, 38, 1542-1557.

Benjamin, A. S., \& Bird, R. D. (2006). Metacognitive control of the spacing of study repetitions. Journal of Memory and Language, 55, 126-137.

Block, R. A., Hancock, P. A., \& Zakay, D. (2010). How cognitive load affects duration judgments: A meta-analytic review. Acta Psychologica, 134, 330-343.

Brewer, G. A., Marsh, R. L., Clark-Foos, A., \& Meeks, J. T. (2010). Noncriterial recollection influence metacognitive monitoring and control processes. Quarterly Journal of Experimental Psychology, 63, 1936-1942.

Bridges, A. M. \& Jones, D. M. (1996). Word dose in the disruption of serial recall by irrelevant speech: Phonological confusions or changing state? Quarterly Journal of Experimental 49A, 919-939.

Brown, G. D. A., Neath, I., \& Chater, N. (2007). A temporal ratio model of memory. Psychological Review, 114, 539-576 
Brown, S. W. (1995). Time, change, and motion: The effects of stimulus movement on temporal perception. Perception \& Psychophysics, 57, 105-116.

Castel, A. D., Murayama, K., Friedman, M. C., McGillivray, S., \& Link, I. (2013). Selecting valuable information to remember: Age-related differences and similarities in self-regulated learning. Psychology \& Aging, 28, 232-242.

Cohen, J. (1988). Statistical power analysis for the behavioral sciences. Hillsdale, N.J: Erlbaum.

Davelaar, E. J., Goshen-Gottstein, Y., Ashkenazi, A., Haarmann, H. J. \& Usher, M. (2005). The demise of short-term memory revisited: empirical and computational investigations of recency effects. Psychological Review, 112, 3-42.

de Jonge, M., Tabbers, H. K., Pecher, D., Jang, Y., \& Zeelenberg, R. (2015). The efficacy of self-paced study in multitrial learning. Journal of Experimental Psychology: Learning, Memory, and Cognition, 41, 851-858.

Dunlosky, J., \& Ariel, R. (2011a). Self-regulated learning and the allocation of study time. In Ross, B. (Ed.), Psychology of Learning and Motivation, Vol. 54 (pp. 101-138).

Dunlosky, J., \& Ariel, R. (2011b). The influence of agenda-based and habitual processes on item selection during study. Journal of Experimental Psychology: Learning, Memory, and Cognition, 37, 899-912.

Dunlosky, J., \& Thiede, K. W. (1998). What make people study more? An evaluation pf factors that affect self-paced study? Acta Psychologica, 98, 37-56.

Frank, D. J., \& Kuhlmann, B. (2017). More than just beliefs: Experience and beliefs jointly contribute to volume effects on metacognitive judgments. Journal of Experimental Psychology: Learning, Memory, and Cognition, 43, 680-693. 
Grenfell-Essam, R., \& Ward, G. (2012). Examining the relationship between free recall and immediate serial recall: The role of list length, strategy use, and test expectancy. Journal of Memory and Language, 67, 106-148.

Grenfell-Essam, R., Ward, G., \& Tan, L. (2013). The role of rehearsal on the output order of immediate free recall of short and long lists. Journal of Experimental Psychology: Learning, Memory, and Cognition, 39, 317-347.

Halin, N., Marsh, J. E., Haga, A., Holmgren, M., \& Sörqvist, P. (2014). Effects of speech on proofreading: Can task-engagement manipulations shield against distraction. Journal of Experimental Psychology: Applied, 20, 69-80.

Hanczakowski, M., Beaman, C. P., \& Jones, D. M. (2016). Negative priming in free recall reconsidered. Journal of Experimental Psychology: Learning, Memory, and Cognition. 42, 686699.

Hanczakowski, M., Beaman, C. P., and Jones, D. M. (2017). When distraction benefits memory through semantic similarity. Journal of Memory and Language, 94, 61-74.

Hanczakowski, M., Zawadzka, K., \& Cockcroft-McKay, C. (2014). Feeling of knowing and restudy choices. Psychonomic Bulletin \& Review, 21, 1617-1622.

Hanczakowski, M., Zawadzka, K., Collie, H., \& Macken, B. (2017). Metamemory in a familiar place: The effects of environmental context on feeling of knowing. Journal of Experimental Psychology: Learning, Memory, and Cognition, 43, 59-71.

Hughes, R. W., Hurlstone, M. J., Marsh, J. E., Vachon, F., \& Jones, D. M. (2013). Cognitive control of auditory distraction: Impact of task difficulty, foreknowledge, and working memory capacity supports duplex-mechanism account. Journal of Experimental Psychology: Learning, Memory, and Cognition, 39, 539-553. 
Hughes, R. W., \& Jones, D. M. (2003). Indispensable benefits and unavoidable costs of unattended sound for cognitive functioning. Noise \& Health, 6, 63-76.

Hussey, E. K., Dougherty, M. R., Harbison, J. I., \& Davelaar, E. J. (2013). Retrieval dynamics in selfterminated memory search. Quarterly Journal of Experimental Psychology, 67, 394-416.

Jones, D. M., Hughes, R. W., \& Macken, W. J. (2010). Auditory distraction and serial memory: The avoidable and the ineluctable. Noise \& Health, 12, 201-209.

Jones, D. M., \& Macken, W. J. (1995). Organizational factors in the effect of irrelevant speech: The role of spatial location and timing. Memory \& Cognition, 23, 192-200.

Jones, D. M., \& Macken, W. J. (1996). Auditory babble and cognitive efficiency: Role of number of voices and their location. Journal of Experimental Psychology: Applied, 1, 216-226.

Jones, D. M., Alford, D., Macken, W. J., Banbury, S. P., \& Tremblay, S. (2000). Interference from degraded auditory stimuli: Linear effects of changing-state in the irrelevant sequence. Journal of the Acoustical Society of America, 108, 1082-1088.

Kanai, R., Paffen, C. L. E., Hogendoorn, H., \& Verstraten, F. A. J. (2006). Time dilation in dynamic visual display. Journal of Vision, 6, 1421-1430.

Karpicke, J. D. (2009). Metacognitive control and strategy selection: Deciding to practice retrieval during learning. Journal of Experimental Psychology: General, 138, 469-486.

Koriat, A., Ma'ayan, H., \& Nussinson, R. (2006). The intricate relationships between monitoring and control in metacognition: Lessons for the cause-and-effect relation between subjective experience and behavior. Journal of Experimental Psychology: General, 135, 36-69.

Kornell, N., \& Metcalfe, J. (2006). Study efficacy and the region of proximal learning framework. Journal of Experimental Psychology: Learning, Memory, and Cognition, 32, 609-622. 
Macken, W. J., Mosdell, N. A., \& Jones, D. M. (1999). Explaining the irrelevant sound effect: Temporal distinctiveness or changing state? Journal of Experimental Psychology: Learning, Memory, and Cognition, 25, 810-814.

Marsh, J. E., Hughes, R. W., \& Jones, D. M. (2008). Auditory distraction in semantic memory: A process-based approach. Journal of Memory and Language, 58, 682-700.

Marsh, J. E., Hughes, R. W., \& Jones, D. M. (2009). Interference by process, not content, determines semantic auditory distraction. Cognition, 110, 23-38.

Marsh, J. E., Sörqvist, P., \& Hughes, R. W. (2015). Dynamic cognitive control of irrelevant sound: Increased task engagement attenuates semantic auditory distraction. Journal of Experimental Psychology: Human Perception and Performance, 41, 1462-1474.

Matthews, W. J., \& Meck, W. H. (2016). Connecting subjective time to perception, attention, and memory. Psychological Bulletin, 142, 865-907.

Mazzoni, G., \& Cornoldi, C. (1993). Strategies in study time allocation: Why is study time sometimes not effective? Journal of Experimental Psychology: General, 122, 47-60.

Metcalfe, J. (2002). Is study time allocated selectively to a region of proximal learning? Journal of Experimental Psychology: General, 131, 349-363.

Metcalfe, J., \& Finn, B. (2008). Evidence that judgments of learning are causally related to study choice. Psychonomic Bulletin \& Review, 15, 174-179.

Middlebrooks, C. D., Kerr, T., \& Castel, A. D. (2017). Selectively distracted: Divided attention and memory for important information. Psychological Science, 28, 1103-1115.

Miles, C., Jones, D. M., \& Madden, C. A. (1991). Locus of the irrelevant speech effect in short-term memory. Journal of Experimental Psychology: Learning, Memory, and Cognition, 17, 578-584. 
Mioni, G., Stablum, F., McClintock, S. M., \& Grondin, S. (2014). Different methods for reproducing time, different results. Attention, Perception, \& Psychophysics, 76, 675-681.

Neely, C. B., \& LeCompte, D. C. (1999). The importance of semantic similarity to the irrelevant speech effect. Memory \& Cognition, 27, 37-44.

Nelson, T. O., Dunlosky, J., Graf, A., \& Narens, L., (1994). Utilization of metacognitive judgments in the allocation of study during multitrial learning. Psychological Science, 5, 207-213.

Nelson, T. O., \& Leonesio, R. J. (1988). Allocation of self-paced study time and the "labor-in-vain effect". Journal of Experimental Psychology: Learning, Memory, and Cognition, 14, 676-686.

Nelson, T. O., \& Narens, L. (1990). Metamemory : A theoretical framework and some new findings. In G. H. Bower (Ed.), The psychology of learning and motivation (Vol. 26, pp. 125-173). San Diego: Academic Press.

Parmentier, F. B. R., \& Beaman, C. P. (2015). Contrasting effects of changing rhythm and content on auditory distraction in immediate memory. Canadian Journal of Experimental Psychology, 69, 28-38.

Pashler, H. \& Wagenmakers, E.-J. (2012). Editors' introduction to the special section on replicability in psychological science. A crisis of confidence? Perspectives on Psychological Science, 7, 528530.

Perfect, T. J., Andrade, J., \& Eagan, I. (2011). Eye-closure reduces the cross-modal memory impairment caused by auditory distraction. Journal of Experimental Psychology: Learning, Memory, and Cognition, 37, 1008-1013.

Perham, N., Hodgetts, H., \& Banbury, S. (2013). Mental arithmetic and non-speech office noise: An exploration of interference-by-content. Noise \& Health, 15, 73-78. 
Polyn, S. M., Norman, K. A., \& Kahana, M. J. (2009). A context maintenance and retrieval model of organizational processes in free recall. Psychological Review, 116, 129-156.

Raaijmakers, J. G. W., \& Shiffrin, R. M. (1981). Search of associative memory. Psychological Review, $88,93-134$.

Rhodes, M. G., \& Castel, A. D. (2008). Memory predictions are influenced by perceptual information: Evidence for metacognitive illusions. Journal of Experimental Psychology: General, 137, 615625.

Richardson, J. T. E. (1998). The availability and effectiveness of reported mediators in associative learning: A historical review and an experimental investigation. Psychonomic Bulletin \& Review, 5, 597-614.

Röer, J. P., Bell, R., \& Buchner, A. (2014). Evidence for habituation of the irrelevant-sound effect on serial recall. Memory \& Cognition, 42, 609-621.

Shelton, J. Elliott, E. M., Eaves, S. D. \& Exner, A. L. (2009). The distracting effects of a ringing cell phone: An investigation of the laboratory and the classroom setting. Journal of Environmental Psychology, 29, 513-521.

Shield, B., \& Dockrell, J. E. (2004). External and internal noise surveys of London primary schools. Journal of the Acoustical Society of America, 115, 730-738.

Shield, B., \& Dockrell, J. E. (2008). The effects of environmental and classroom noise on the academic attainments of primary school children. Journal of the Acoustical Society of America, 123, 133144.

Soderstrom, N. C., \& Bjork, R. A. (2014). Testing facilitates the regulation of subsequent study time. Journal of Memory and Language, 73, 99-115. 
Son, L. K., \& Metcalfe, J. (2000). Metacognitive and control strategies in study-time allocation. Journal of Experimental Psychology: Learning, Memory, and Cognition, 26, 204-221.

Tan, L., \& Ward, G. (2000). A recency-based account of primacy effects in free recall. Journal of Experimental Psychology: Learning, Memory, and Cognition, 26, 1589-1625.

Tan, L., \& Ward, G. (2007). Output order in immediate serial recall. Memory \& Cognition, 35, 10931106.

Thiede, K. W., \& Dunlosky, J. (1999). Toward a general model of self-regulated study: An analysis of selection of items for study and self-paced study time. Journal of Experimental Psychology: Learning, Memory, and Cognition, 25, 1024-1037.

Tremblay, S., Parmentier, F. B. R., Hodgetts, H. M., Hughes, R. W., \& Jones, D. M. (2012). Disruption of verbal-spatial serial memory by extraneous air-traffic speech. Journal of Applied Research in Memory and Cognition, 1, 73-79.

Tullis, J. G., \& Benjamin, A. S. (2011). On the effectiveness of self-paced learning. Journal of Memory and Language, 64, 109-118.

Tullis, J. G., \& Benjamin, A. S. (2012). Consequences of restudy choices in younger and older learners. Psychonomic Bulletin \& Review, 19, 743-749.

Undorf, M., \& Erdfelder, E. (2015). The relatedness effect on judgments of learning: A closer look at the contribution of processing fluency. Memory \& Cognition, 43, 647-658.

Unsworth, N. (2016). Working memory capacity and recall from long-term memory: Examining the influences of encoding strategies, study time allocation, search efficiency, and monitoring abilities. Journal of Experimental Psychology: Learning, Memory, and Cognition, 42, 50-61. 
Ward, G., Tan, L., \& Grenfell-Essam, R. (2010). Examining the relationship between free recall and immediate serial recall: The effects of list length and output order. Journal of Experimental Psychology: Learning, Memory, and Cognition, 36, 1207-1241.

Yoon, C., Feinberg, F., Hu, P., Gutchess, A. H., Hedden, T., Chen, H.-Y. M., Jing, Q., Cui, Y., \& Park, D. C. (2004). Category norms as a function of culture and age: Comparisons of item responses to 105 categories by American and Chinese adults. Psychology and Aging, 19, 379-393.

Zeamer, C., \& Fox Tree, J. E. (2013). The process of auditory distraction: Disrupted attention and impaired recall in a simulated lecture environment. Journal of Experimental Psychology: Learning, Memory, and Cognition, 39, 1463-1472. 
Table 1.

Mean correct recall scores and mean aggregate judgments-of-learning presented as a function of locus of control over study times (participant vs. experimenter) and distraction condition in Experiments 2-6 and 8. Standard errors of the means are given in parentheses.

\begin{tabular}{|c|c|c|c|c|}
\hline & \multicolumn{2}{|c|}{ Participants' control over study times } & \multicolumn{2}{|c|}{$\begin{array}{c}\text { Experimenter's control over study } \\
\text { times }\end{array}$} \\
\hline & Auditory distraction & Quiet & Auditory distraction & Quiet \\
\hline \multicolumn{5}{|l|}{ Experiment 2} \\
\hline Correct recall & $.47(.02)$ & $.52(.03)$ & $.49(.02)$ & $.53(.02)$ \\
\hline Aggregate JOLs & $.45(.02)$ & $.50(.02)$ & $.44(.02)$ & $.49(.02)$ \\
\hline \multicolumn{5}{|l|}{ Experiment 3} \\
\hline Correct recall & $.44(.02)$ & $.52(.02)$ & $.41(.02)$ & $.49(.02)$ \\
\hline Aggregate JOLs & $.42(.02)$ & $.48(.02)$ & $.39(.02)$ & $.45(.02)$ \\
\hline \multicolumn{5}{|l|}{ Experiment 4} \\
\hline Correct recall & $.40(.03)$ & $.52(.03)$ & $.40(.03)$ & $.47(.03)$ \\
\hline Aggregate JOLs & $.37(.02)$ & $.46(.03)$ & $.38(.02)$ & $.43(.02)$ \\
\hline \multicolumn{5}{|l|}{ Experiment 5} \\
\hline Correct free recall & $.44(.03)$ & $.55(.03)$ & $.40(.03)$ & $.48(.02)$ \\
\hline Correct stem-cued recall & $.45(.03)$ & $.54(.03)$ & $.43(.03)$ & $.49(.02)$ \\
\hline \multicolumn{5}{|l|}{ Experiment 6} \\
\hline Correct recall & $.49(.02)$ & $.58(.02)$ & - & - \\
\hline \multicolumn{5}{|l|}{ Experiment 8} \\
\hline Correct recall & $.56(.04)$ & $.59(.04)$ & - & - \\
\hline Aggregate JOLs & $.34(.02)$ & $.42(.03)$ & - & - \\
\hline
\end{tabular}


Table 2.

Mean study times (in ms) per word presented as a function of distraction condition in Experiments 28. Cohen's ds and $p$ values for the comparisons of mean study times are also included. Standard errors of the means are given in parentheses.

\begin{tabular}{|c|c|c|c|c|}
\hline & Auditory distraction & Quiet & Cohen's $d$ & $p$ value \\
\hline Experiment 2 & 2211 (197) & $2439(238)$ & 0.423 & .028 \\
\hline Experiment 3 & $2590(160)$ & $2948(185)$ & 1.035 & $<.001$ \\
\hline Experiment 4 & $2563(184)$ & $3108(191)$ & 0.825 & $<.001$ \\
\hline \multicolumn{5}{|l|}{ Experiment 5} \\
\hline Free recall condition & $2828(160)$ & $3320(198)$ & 0.620 & $<.001$ \\
\hline Stem-cued recall condition & $2910(175)$ & $3340(194)$ & 0.915 & $<.001$ \\
\hline Experiment 6 & 2900 (134) & $3271(126)$ & 1.738 & $<.001$ \\
\hline Experiment 7 & $3031(90)$ & $3280(84)$ & 1.246 & $<.001$ \\
\hline Experiment 8 & 4071 (194) & $4162(196)$ & 0.208 & .233 \\
\hline
\end{tabular}


Figure Legends.

Figure One: Experiment 1: The effects of auditory distraction on memory recall and Judgments of Learning (JOLs).

Figure Two: Experiment 1: The effects of auditory distraction on study time.

Figure Three: Experiment 1: Effects of auditory distraction by semantically related and unrelated speech on memory recall broken down by serial position.

Figure Four: Experiment 1: Aggregate Judgments of Learning (JOLs) as a function of the distraction condition and list. 
Figure 1.

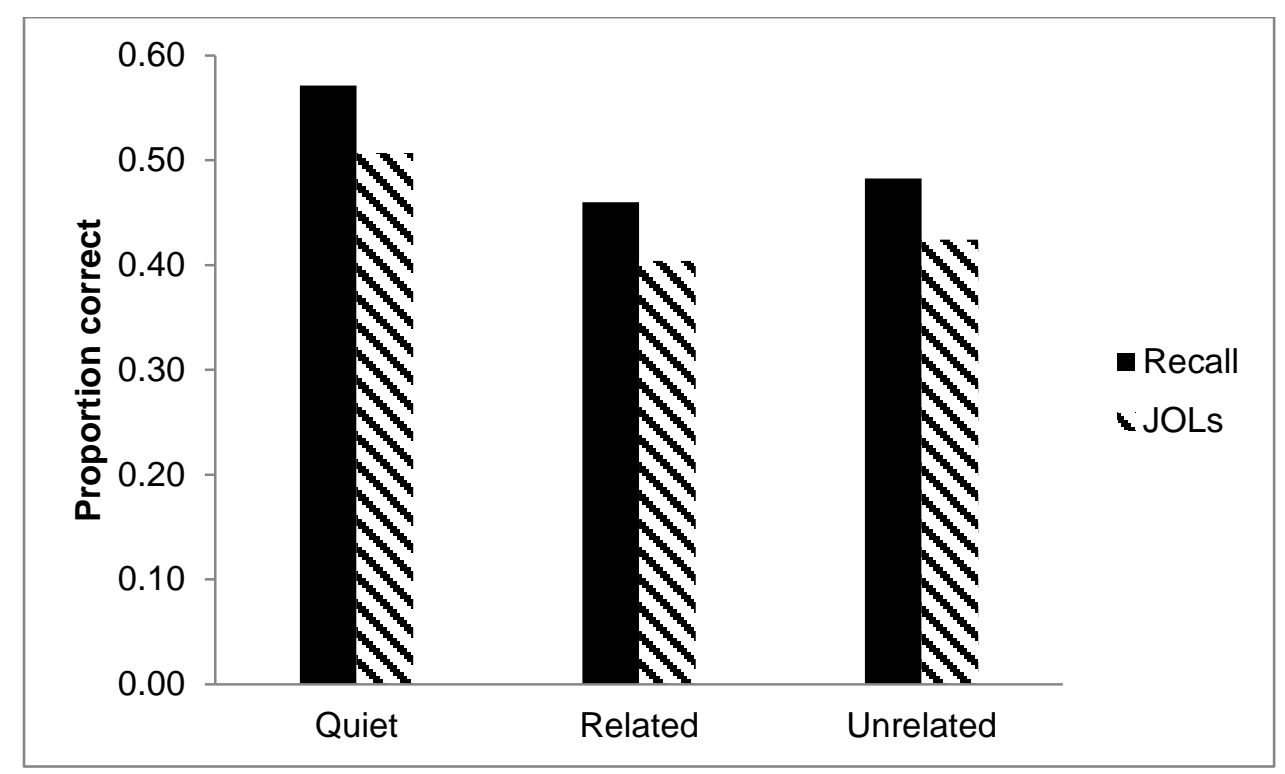


Figure 2.

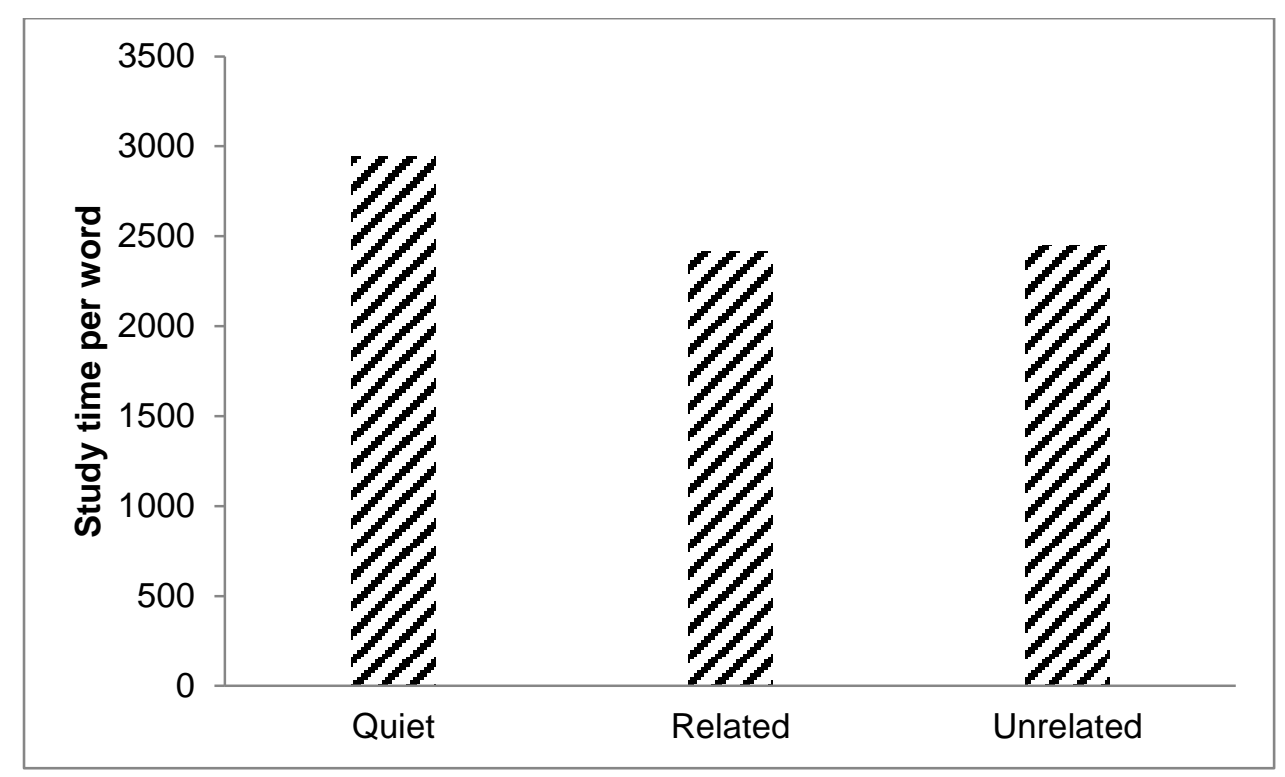


Figure 3.

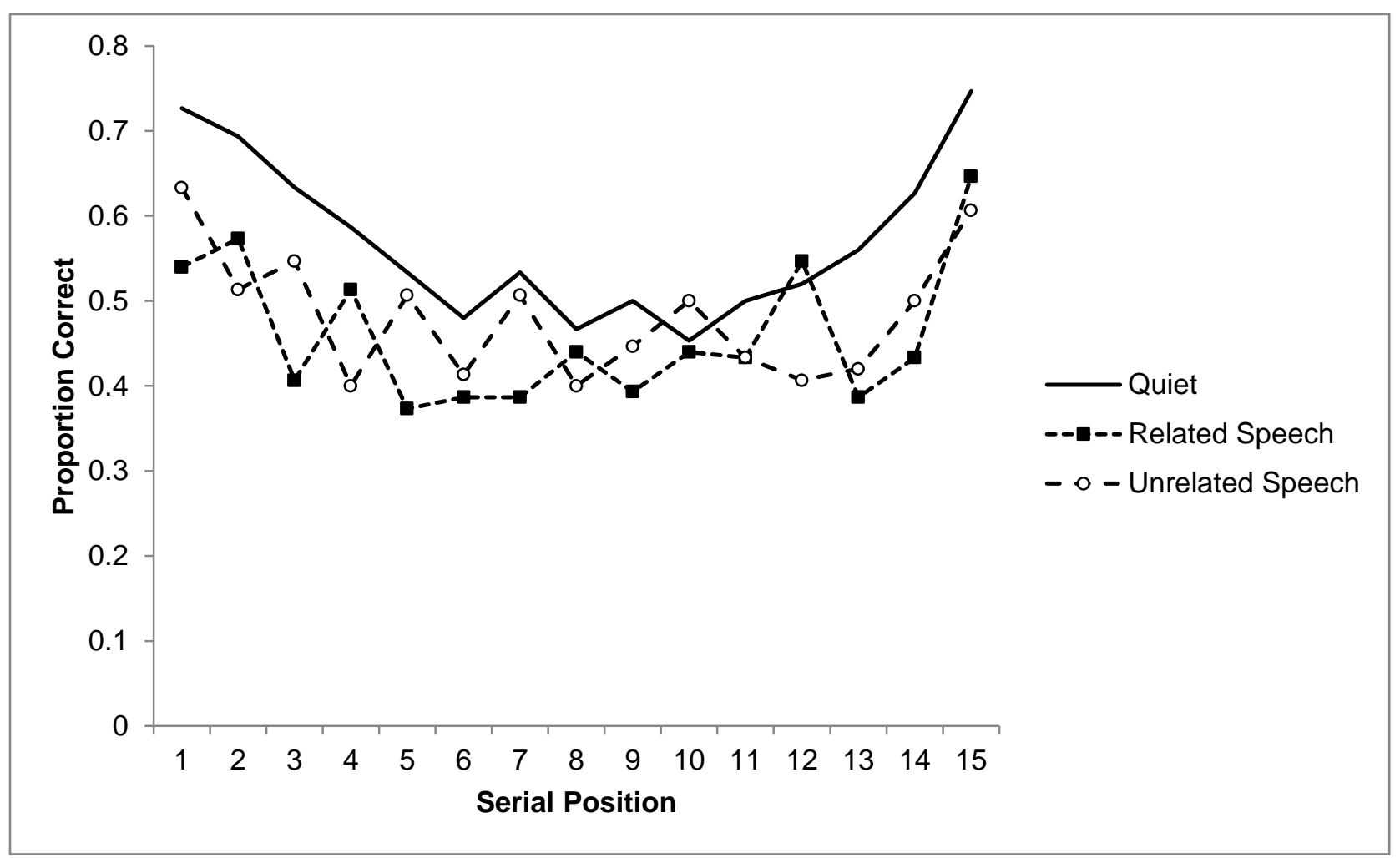


Figure 4.

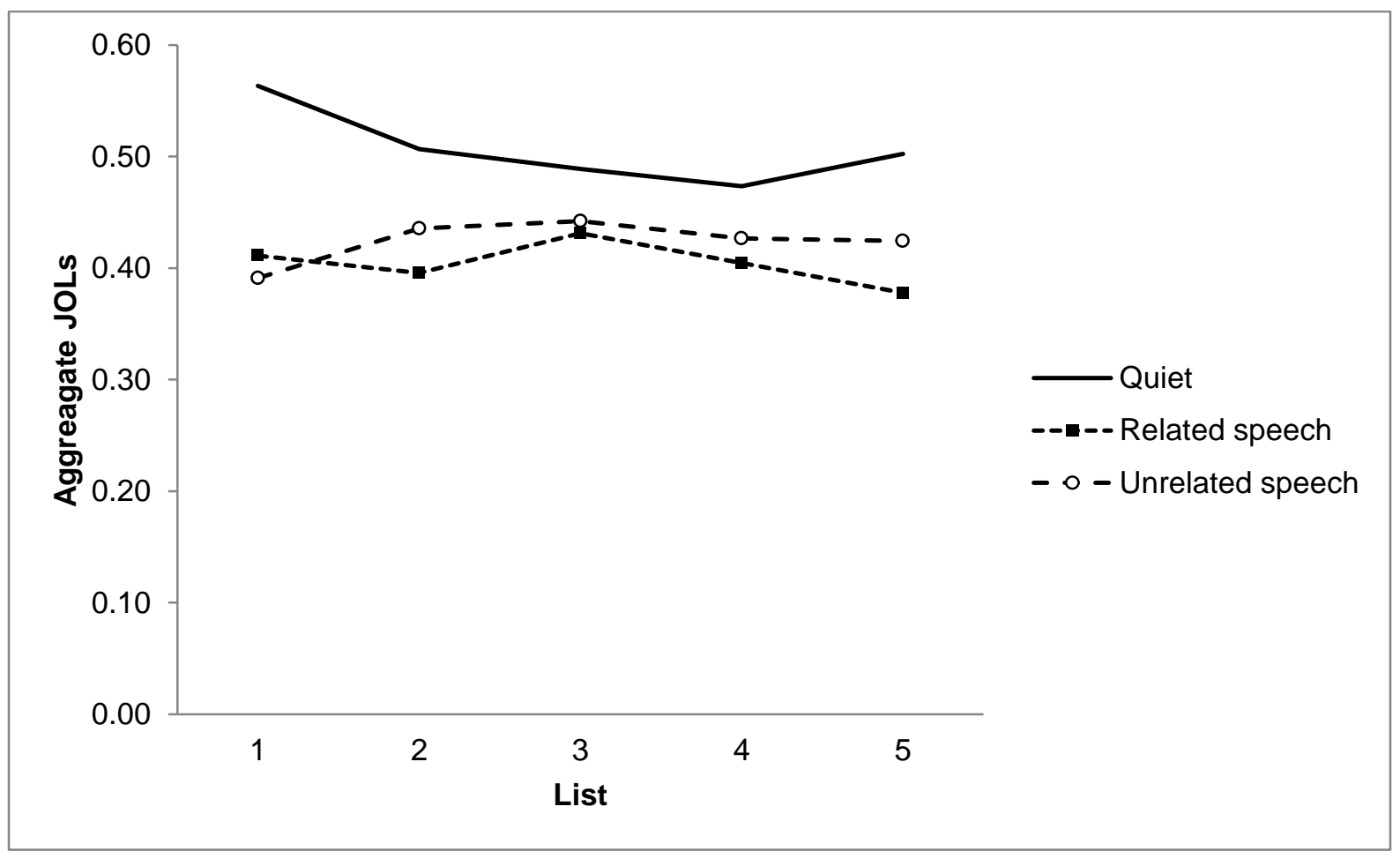

